\title{
Cell wall composition and digestibility alterations in Brachypodium distachyon achieved through reduced expression of the UDP-arabinopyranose mutase
}

\author{
David M. Rancour ${ }^{1}$, Ronald D. Hatfield ${ }^{1 *}$, Jane M. Marita ${ }^{1}$, Nicholas A. Rohr ${ }^{2}$ and \\ Robert J. Schmitz ${ }^{2}$ \\ 1 U.S. Dairy Forage Research Center, United States Department of Agriculture - Agricultural Research Service, Madison, WI, \\ USA, ${ }^{2}$ Department of Genetics, University of Georgia, Athens, GA, USA
}

\section{OPEN ACCESS}

Edited by:

Soren K. Rasmussen, University of Copenhagen, Denmark

Reviewed by: Henrik Scheller,

Lawrence Berkeley National Laboratory, USA Kanwarpal Singh Dhugga,

DuPont Pioneer, USA

*Correspondence:

Ronald D. Hatfield,

U.S. Dairy Forage Research Center,

United States Department of Agriculture - Agricultural Research Service, 1925 Linden Drive, Madison,

WI 53706, USA

ronald.hatfield@ars.usda.gov

Specialty section

This article was submitted to

Plant Biotechnology,

a section of the journal

Frontiers in Plant Science

Received: 09 April 2015 Accepted: 31 May 2015

Published: 17 June 2015

Citation:

Rancour DM, Hatfield RD, Marita JM

Rohr NA and Schmitz RJ (2015) Cell

wall composition and digestibility

alterations in Brachypodium

distachyon achieved through reduced expression of the

UDP-arabinopyranose mutase.

Front. Plant Sci. 6:446. doi: 10.3389/fp/s.2015.00446
Nucleotide-activated sugars are essential substrates for plant cell-wall carbohydratepolymer biosynthesis. The most prevalent grass cell wall (CW) sugars are glucose (Glc), xylose (Xyl), and arabinose (Ara). These sugars are biosynthetically related via the UDP-sugar interconversion pathway. We sought to target and generate UDP-sugar interconversion pathway transgenic Brachypodium distachyon lines resulting in CW carbohydrate composition changes with improved digestibility and normal plant stature. Both RNAi-mediated gene-suppression and constitutive gene-expression approaches were performed. CWs from $336 \mathrm{~T}_{0}$ transgenic plants with normal appearance were screened for complete carbohydrate composition. RNAi mutants of BdRGP1, a UDParabinopyranose mutase, resulted in large alterations in CW carbohydrate composition with significant decreases in CW Ara content but with minimal change in plant stature. Five independent RNAi-RGP1 $\mathrm{T}_{1}$ plant lines were used for in-depth analysis of plant CWs. Real-time PCR analysis indicated that gene expression levels for BdRGP1, $B d R G P 2$, and BdRGP3 were reduced in RNAi-RGP1 plants to $15-20 \%$ of controls. CW Ara content was reduced by $23-51 \%$ of control levels. No alterations in CW Xyl and Glc content were observed. Corresponding decreases in CW ferulic acid (FA) and ferulic acid-dimers (FA-dimers) were observed. Additionally, CW p-coumarates (pCA) were decreased. We demonstrate the CW $p C A$ decrease corresponds to Ara-coupled pCA. Xylanase-mediated digestibility of RNAi-RGP1 Brachypodium CWs resulted in a near twofold increase of released total carbohydrate. However, cellulolytic hydrolysis of CW material was inhibited in leaves of RNAi-RGP1 mutants. Our results indicate that targeted manipulation of UDP-sugar biosynthesis can result in biomass with substantially altered compositions and highlights the complex effect CW composition has on digestibility.

Keywords: plant cell wall, biomass, Brachypodium distachyon, grass, nucleotide-sugar, hydroxycinnamates

Notes: Mention of a trademark or proprietary product does not constitute a guarantee or warranty of product by the USDA nor does it imply approval to the exclusion of other suitable products. 


\section{Introduction}

The plant CW is a complex mixture of carbohydrates, aromaticcompounds, and protein that is critical for plant form and function whilst comprising the largest source of renewable biomass on earth (Pauly and Keegstra, 2008). This lignocellulosic biomass material is used for food, feed, fiber, and energy-inputs. The acknowledgment of climate change and the need to support the growing global human population's need for food and energy has put a high demand on technology development to maximize plant biomass production and utilization for sustainable and renewable sources of food, feed, fiber, and energy (FAO, 2003). Approaches to improve biomass quality, use-efficiency, and yields are needed.

The efficient extractability of CW carbohydrate is a major limitation in use-efficiency with many different proposed molecular solutions made to improve it (Hatfield et al., 1999c; McCann and Carpita, 2008; Pauly and Keegstra, 2008; Carroll and Somerville, 2009; Pauly and Keegstra, 2010; Jung et al., 2012; Doblin et al., 2014; Kalluri et al., 2014). Plant CW compositions are not uniform and vary according to many factors including species source, organ/tissue source, and developmental stage. The feasibility and efficacy of the proposed approaches may be plant species-dependent.

In monocots, the principle $\mathrm{CW}$ carbohydrate polymers are cellulose, $\beta$-glucans $[(1,3 ; 1,4)-\beta$-D-glucans $]$, and arabinoxylans (Carpita, 1996) with Glc, Xyl, and Ara dominating the CW carbohydrate profile (Pauly and Keegstra, 2008). The plant CW can be considered a metabolic sink for carbohydrate. Sugar biosynthesis and availability is critical to provide sufficient substrate for CW polysaccharide biosynthesis throughout plant growth and development.

Nucleotide-sugars are the principle carbohydrate-donor substrates for the glycosyltransferases involved in plant CW polysaccharide biosynthesis (Reiter, 2008; Bar-Peled and O'Neill, 2011). Biosynthesis of UDP- $\alpha-D-X y l$ and UDP- $\beta-L-A r a$ can be derived from a linear pathway initiating with UDP- $\alpha-D-$ Glc. The conversion of UDP- $\alpha$-D-Glc to UDP- $\alpha$-D-glucuronic acid (GlcA) by the UDP- $\alpha-D-G l c$ dehydrogenase (UGD) is the first committed step in the pathway (Tenhaken and Thulke, 1996). Subsequent steps are catalyzed by consecutive enzymes including: (a) UDP- $\alpha-D-G l c A$ decarboxylase (UXS) to make UDP- $\alpha$-D-Xyl (Harper and Bar-Peled, 2002), (b) UDP- $\alpha$-D-Xyl epimerase (UXE) to make UDP- $\beta$-L-Arap (Burget et al., 2003), and (c) UDP- $\beta$-L-Ara $p$ mutase (UAM; alternatively know as RGP or "reversibly glycosylated protein") to make UDP- $\beta$-L-Araf (Dhugga et al., 1997; Delgado et al., 1998; Konishi et al., 2007). A bifunctional pathway branch enzyme, UDP- $\alpha$-D-apiose/UDP$\alpha-D-X y l$ synthase (AXS), exists that utilizes UDP- $\alpha-D-G l c A$

Abbreviations: Ara, arabinose; Araf, arabinofuranose; Arap, arabinopyranose; AXS, UDP-apiose/UDP-xylose synthase; CW, cell wall; FA, ferulic acid; Fuc, fucose; Gal, galactose; Glc, glucose; Man, mannose; $p \mathrm{CA}, p$-coumaric acid; RGP, reversibly glycosylated protein; Rha, rhamnose; RNAi, RNA-mediated interference; UAM, UDP-arabinopyranose mutase; UDP-Araf, uridine diphospho arabinofuranose; UDP-Arap, uridine diphospho arabinopyranose; UGD, UDPglucose dehydrogenase; UXE, UDP-xylose epimerase; UXS, UDP-xylose synthase; Xyl, xylose. to make UDP- $\alpha$-D-apiose (Api) and UDP- $\alpha-\mathrm{D}-\mathrm{Xyl}$ (Mølhøj et al., 2003). UDP- $\alpha$-D-apiose is a critical component for rhamnogalacturonan II (RG-II) pectin biosynthesis. Phylogenetic analysis of representative family members has been performed (Yin et al., 2011) highlighting the conservation of this pathway in plants. Recent work has demonstrated that certain classes of UDP- $\alpha$-D-Glc 4-epimerase are bifunctional and can epimerize UDP- $\alpha$-D-Xyl to UDP- $\beta$-L-Ara $p$ (Kotake et al., 2009).

Analysis of CWs from plants of mutants or altered expression of select genes encoding enzymes of this pathway has been performed in dicots including Arabidopsis UGD (Reboul et al., 2011; Behmüller et al., 2014), UXE (Burget et al., 2003), and UAM/RGP (Rautengarten et al., 2011), Nicotiana benthamiana AXS (Ahn et al., 2006), and alfalfa UGD (Samac et al., 2004). In vivo $\mathrm{CW}$ consequences of altered expression of this pathway have been limited in monocots and include such examples as maize UGD (Karkonen et al., 2005) and rice UAM/RGP (Konishi et al., 2011). In these presented cases, strong and negative consequences on $\mathrm{CW}$ formation and/or plant form and biomass production were observed.

Our hypothesis is that controlled manipulation of the biosynthesis of the nucleotide sugar substrates for CW polysaccharide biosynthesis could lead to changes in $\mathrm{CW}$ composition to improve $\mathrm{CW}$ digestibility but not affect plant growth and biomass production. We sought to explore manipulation of this UDP-sugar interconversion pathway in Brachypodium distachyon, a model C3 grass for forage grass research (Brkljacic et al., 2011; Mur et al., 2011; Philippe, 2011; Rancour et al., 2012; Girin et al., 2014). Targeting the UDP-sugar interconversion pathway in principle could lead directly to alterations in arabinoxylan and pectin structure, and in-directly into alterations in (1) CW crosslinking via hydroxycinnamates and (2) cellulose and/or $\beta$-glucans. For example, changes in the availability of UDP-GlcA, UDP-Xyl, and UDP-Ara would directly affect hemicellulose (Scheller and Ulvskov, 2010) and pectin (Atmodjo et al., 2013) biosynthesis but also indirectly affect FA-mediated crosslinking of CW components (Hatfield et al., 1999b; de O Buanafina, 2009). If the pathway is inhibited at the first committed step, then backup of UDP-Glc could lead to changes in CW cellulose and/or $\beta$-glucan content. However, little information regarding the relationship of (1) gene expression, (2) enzymatic-activity capacity for substrate biosynthesis, membrane transporters, and CW polysaccharide glycosyltransferases, and (3) overall metabolic flux is currently available in grasses to accurately predict the feasibility and outcome of these different scenarios on CW composition.

Therefore as a first step, the objectives of our study were to (1) characterize the expression of the UDP-sugar interconverting enzyme-encoding genes from $B$. distachyon and (2) use complementary RNAi and constitutive gene expression approaches to determine whether changes in gene expression would lead to alterations in CW composition without grossly affecting plant growth. We have identified RNAi-mutants in the Brachypodium RGP1 which have reduced CW-bound Ara and hydroxycinnamates. RNAi-mutants exhibit increased xylan digestibility and decreased cellulose digestibility while not affecting plant stature. These data support the efficacy 
of a selection-scheme where mutant plants of near wildtype stature are screened for $\mathrm{CW}$ composition phenotypes. In addition, these data highlight the complexity of grass $\mathrm{CW}$ composition and ways to manipulate that complexity to improve digestibility.

\section{Materials and Methods}

\section{General}

All DNA primers (Supplementary Table S1) were synthesized by the DNA Synthesis Facility in the University of WisconsinMadison Biotechnology Center. All routine PCR (including colony PCR, A-tailing cDNA products, and transgenic plant screening) was performed using EconoTaq ${ }^{\circledR}$ PLUS GREEN 2X master mix (Lucigen Corporation, Middleton, WI, USA). All DNA restriction and modifying reagents, unless noted otherwise, were obtained from New England Biolabs (Ipswich, MA, USA). All DNA sequencing was performed with ABI BigDye ${ }^{\text {TM }}$ Terminator reagents (Applied Biosystems-Life Technologies), Agencourt $^{\mathrm{TM}}$ CleanSEQ ${ }^{\mathrm{TM}}$ (Agencourt Biosciences Corporation, Beverly, MA, USA) magnetic bead clean-up, and analyzed at the DNA Sequencing Facility in the University of WisconsinMadison Biotechnology Center.

\section{Vector Cloning}

A modified, Gateway-cloning compatible in planta RNAi vector, based on the Ubilp expression cassette for the pANDA series of monocot RNAi vectors (Miki and Shimamoto, 2004; Miki et al., 2005), was constructed essentially as described (Marita et al., 2014). One change to the previous construct was that the pPZP211 binary vector backbone (Hajdukiewicz et al., 1994) was used here in place of pPZP221b (Kang et al., 2001). The pPZP211 utilizes a CaMV 35S expression cassette controlling the expression of the neomycin phosphotransferase II plant selection marker.

A constitutive expression binary vector based on the Ub1 promoter-Gateway cassette from the pANDA mini vector (Miki and Shimamoto, 2004) was generated. The pANDA mini vector was digested with KpnI and EcoRV, overhang ends blunted with the NEB Rapid Blunting kit, and the resulting vector was ligated and transformed in to $c c d B$ Survival ${ }^{\mathrm{TM}} 2 \mathrm{~T}^{\mathrm{R}}$ E. coli (InvitrogenLife Technologies). This processing resulted in a deletion of a $\sim 2.7 \mathrm{~kb}$ fragment containing the first Gateway cassette and the Gus linker of the pANDA mini RNAi hairpin cassette bringing the forward sense Gateway cassette 2 directly adjacent to the Ub1 promoter. The resulting plasmid was called $p A N D A-O X$

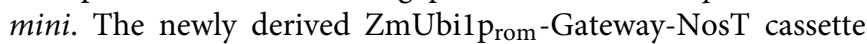
was PCR amplified (Finnzyme Phusion DNA polymerase) using primers $\mathrm{RH} 12$ and $\mathrm{RH} 13$ that introduced flanking FspI restriction sites. The PCR product was gel purified, phosphorylated with T4 polynucleotide kinase, and directly ligated into prepared pPZP211. The pPZP211 vector was prepared by restriction digest with EcoRI and blunting using T4 DNA polymerase. The presence and orientation of the insert was screened by restriction digest of isolated plasmid DNA using XhoI. The final empty binary vector, pPZP211-OX, was verified by DNA sequencing using primers RH3, RH4, RH5, RH6, RH10, RH11, RH14, and RH15.

\section{Brachypodium distachyon Nucleotide-Sugar Interconversion Enzyme-Encoding Gene Cloning}

Brachypodium distachyon genes encoding homologs of UDPsugar interconverting enzymes were identified via TBLASTN searches (Madden, 2013) of the $B$. distachyon Bd21 genome sequence (International Brachypodium Initiative, 2010) using protein sequences for Arabidopsis, rice, and maize homologs with verified function. Predicted protein sequences were obtained from NCBI. Protein sequence alignments and phylogenetic trees were generated using Lasergene MegAlign software (DNAstar, Madison, WI, USA) with the ClustalW multi-sequence alignment method using default parameters and the Gonnet-series proteinweight matrix. One thousand bootstrapping test trials were used for phylogenetic tree refinement.

DNA-free total RNA was isolated from frozen-ground $B$. distachyon Bd21-3 (Vogel and Hill, 2008) 7-days old whole seedlings and total aerial parts of 7-weeks old plants using the Spectrum $^{\text {TM }}$ Plant Total RNA kit (Sigma-Aldrich, St. Louis, MO, USA) according to manufacturer's protocol A. Total RNA yields and purity were calculated after spectrophotometer absorbance measurements at 260, 280, and $320 \mathrm{~nm}$. First strand cDNA synthesis was performed using the GoScript ${ }^{\mathrm{TM}}$ Reverse Transcription System (Promega, Madison, WI, USA) and a poly$\mathrm{T}$ primer. One microgram of total RNA was used for cDNA synthesis reactions used for cloning.

PCR amplification of cDNAs for UGD1, UGD2, UGD3, UXS4, UXS6, UXE1, UXE2, UXE3, and AXS including coding sequence and partial $5^{\prime}$ - and $3^{\prime}$-UTRs was performed using gene specific primers (Supplementary Table S2) and Phusion ${ }^{\mathrm{TM}}$ high-fidelity DNA polymerase. Purified amplification products were 'A-tailed' and T-A sub-cloned into pGEM-T easy (Promega Corporation, Madison, WI, USA). The resulting clones were verified by DNA sequencing using primers $\mathrm{RH} 8$, and RH9 and DNA sequence analysis against the BD21 genome sequence was performed using DNAStar Lasergene software (DNAStar, Madison, WI, USA) (Supplementary Tables S3).

Sequence-verified T-A-cloned cDNAs were cloned into pENTR2B as follows. The pGEMT-easy cDNA vector DNA was digested with either NotI or EcoRI and blunted with the NEB Rapid Blunting Kit. The pENTR2B vector was double-digested with XmnI and EcoRV, de-phosphorylated with Antarctic Phosphatase (NEB), and T4 DNA ligase-mediated ligation reactions with added blunted-cDNAs were performed. Insert orientation was determined by PCR using pENTR2Bspecific RH63 and 3'-cDNA-specific primers.

The cDNAs for UXS2, RGP1, RGP2, and RGP4 were PCR amplified using Phusion ${ }^{\mathrm{TM}}$ high-fidelity DNA polymerase and gene-specific primers (Supplementary Table S2) and cloned into pENTR-D-TOPO using the $\mathrm{pENTR}^{\mathrm{TM}}$ Directional TOPO ${ }^{\circledR}$ Cloning Kit according to manufacturer's instructions (Life Technologies). The resulting plasmids were validated by DNA sequencing using primers RH8 and RH9 (Supplementary Table S3). 
Deletion mutant cDNAs used for construction of RNAi vectors were made by endonuclease-mediated removal of regions targeted by gene-specific qRT-PCR for endogenous transcript detection from pENTR-cDNA plasmids. Enzymes used and characteristics of regions removed and remaining are found in Supplementary Table S4.

To facilitate detection of constitutive expressed gene products, pENTR-cDNA plasmids for UGD1, UXS2, UXS6, UXE1, and AXS were modified to include a translatable C-terminal hemagglutinin protein peptide tag (HA-tag; YPYDVPDYA-stop). Plasmids were linearized by PCR using reverse orientation primers (see Table $\mathbf{1}$ ) and Phusion ${ }^{\mathrm{TM}}$ high-fidelity DNA polymerase followed by DpnI-treatment of the resulting reaction mix with the products spin-column purified. Phosphorylated $\left(5^{\prime}\right)$ oligos (HA-forward and HA-reverse) encoding the HA-tag with a stop codon were self-annealed by mixing an equal molar ratio (10 $\mu \mathrm{L}$ of $100 \mu \mathrm{M}$ each in $\mathrm{TE}$ ), heated to $95^{\circ} \mathrm{C}$ in a thermalcycler and allowed to cool to $4^{\circ} \mathrm{C}$ over $5 \mathrm{~min}$. Annealed oligos were diluted with TE 10 -fold and used directly in T4 DNA ligasemediated ligation reactions with linearized plasmids (above). The resulting clones were screened by colony PCR using HAtag and RH63 primers. The resulting plasmids were validated by single-pass DNA sequencing using primer RH63.

Gene-specific RNAi- and constitutive-expression binary vectors were generated using Gateway ${ }^{\circledR}$ LR Clonase ${ }^{\mathrm{TM}}$ II enzyme mix (Life Technologies) in miniature reactions. The reactions included $\sim 150 \mathrm{ng}$ pENTR-cDNA, $\sim 150$ ng destination vector,

TABLE 1 | Classification and nomenclature used for Brachypodium distachyon genes encoding UDP-sugar inter-conversion pathway enzymes.

\begin{tabular}{|c|c|c|c|c|}
\hline $\begin{array}{l}\text { Encoded } \\
\text { enzyme }\end{array}$ & EC & $\begin{array}{l}\text { Abbreviated } \\
\text { name }\end{array}$ & Gene locus & $\begin{array}{l}\text { B. distachyon } \\
\text { nomenclature }\end{array}$ \\
\hline \multirow{3}{*}{$\begin{array}{l}\text { UDP-glucose } \\
\text { 6-dehydrogenase }\end{array}$} & \multirow[t]{3}{*}{1.1 .1 .22} & \multirow[t]{3}{*}{ UGD } & Bradi1g08120 & UGD1 \\
\hline & & & Bradi4g25140 & UGD2 \\
\hline & & & Bradi1g10650 & UGD3 \\
\hline \multirow{6}{*}{$\begin{array}{l}\text { UDP-xylose } \\
\text { synthase } \\
\text { (UDP-glucuronic } \\
\text { acid } \\
\text { decarboxylase) }\end{array}$} & \multirow[t]{6}{*}{ 4.1.1.35 } & \multirow[t]{6}{*}{ UXS } & Bradi1g66230 & UXS1 \\
\hline & & & Bradi2g54380 & UXS2 \\
\hline & & & Bradi2g11960 & UXS3 \\
\hline & & & Bradi2g27870 & UXS4 \\
\hline & & & Bradi1g18020 & UXS5 \\
\hline & & & Bradi1g66440 & UXS6 \\
\hline \multirow{3}{*}{$\begin{array}{l}\text { UDP-xylose } \\
\text { 4-epimerase }\end{array}$} & \multirow[t]{3}{*}{ 5.1.3.5 } & \multirow[t]{3}{*}{ UXE } & Bradi5g21930 & UXE1 \\
\hline & & & Bradi1g58080 & UXE2 \\
\hline & & & Bradi3g14260 & UXE3 \\
\hline \multirow{4}{*}{$\begin{array}{l}\text { UDP- } \\
\text { arabinopyranose } \\
\text { mutase } \\
\text { (Reversibly } \\
\text { Glycosylated } \\
\text { Protein) }\end{array}$} & \multirow[t]{6}{*}{ 5.4.99.30 } & \multirow[t]{4}{*}{ RGP (UAM) } & Bradi1g15050 & RGP1 \\
\hline & & & Bradi1g21990 & RGP2 \\
\hline & & & Bradi2g50660 & RGP3 \\
\hline & & & Bradi5g24850 & RGP4 \\
\hline $\begin{array}{l}\text { UDP- } \\
\text { apiose/UDP- } \\
\text { xylose } \\
\text { synthase }\end{array}$ & & AXS & Bradi2g61940 & AXS \\
\hline $\begin{array}{l}\text { Expression } \\
\text { control gene }\end{array}$ & & UBC18 & Bradi4g00660 & UBC18 \\
\hline
\end{tabular}

and Tris/EDTA (TE) pH 8.0 all to a volume of $5 \mu$ l. One microliter of LR Clonase ${ }^{\mathrm{TM}}$ II enzyme mix was added and reactions were allowed to proceed for $1 \mathrm{~h}$ to overnight at room temperature. Reactions were terminated by adding $0.5 \mu \mathrm{L}$ Proteinase K (supplied with LR Clonase kit), incubated for $15 \mathrm{~min}$ at $37^{\circ} \mathrm{C}$, and then transformed into chemically competent DH5a E. coli. The resulting plasmids were verified by (1) endonuclease restriction digests and (2) DNA sequencing over recombination junctions using primers RH3, RH10, RH98, and RH99.

\section{RNA-seq Library Preparation, Sequencing, and Analysis}

Total RNA was isolated as above from B. distachyon Bd21-3 plant tissues used for previous CW analysis (Rancour et al., 2012). RNA-seq libraries were constructed using Illumina TruSeq Stranded RNA LT Kit following the manufacturer's instructions with limited modifications. The starting quantity of total RNA was adjusted to $1.3 \mu \mathrm{g}$, and all volumes were reduced to a third of the described quantity. Sequencing of libraries was performed up to 100 cycles. Image analysis and base calling were performed with the standard Illumina pipeline. Illumina HiSeq2500 output files in the FASTQ format were aligned to a SNP-substituted Bd21-3 B. distachyon reference genome using Bowtie version 2.1.0 (Langmead and Salzberg, 2012) and Tophat version 2.0.8b (Kim et al., 2013; flags = -F 0 - i $30-$ M). Gene expression values were calculated using Cufflinks version 2.1.1 (flags $=-\mathrm{u}$-library type fr-firststrand -b; Trapnell et al., 2013).

\section{Plant Transformation}

The Bd21-3 accession was used for Agrobacterium-mediated plant transformation based on the method of Vogel and Hill (2008) with several modifications. Primary embryonic callus was cultured for 4 weeks on solidified Brachypodium callus induction medium (BCIM) [for $1 \mathrm{~L}: 4.43 \mathrm{~g} \mathrm{LS}$ salts with vitamins, $30 \mathrm{~g}$ sucrose, $1 \mathrm{~mL} 0.6 \mathrm{mg} \mathrm{mL}^{-1} \mathrm{CuSO}_{4}$, pH 5.8 with $0.1 \mathrm{M} \mathrm{KOH}, 2 \mathrm{~g}$ Gelzan (Caisson Labs, North Logan, UT, USA); after autoclaving add $0.5 \mathrm{~mL}$ of $5 \mathrm{mg} \mathrm{mL}^{-1}$ 2,4-dichlorophenoxyacetic acid (2,4D)] and high-quality callus was fragmented and sub-cultured one time for one week prior to co-cultivation with Agrobacterium. The Agrobacterium-strain AGL1 (Lazo et al., 1991) was used for all experiments. Agrobacterium strains were streaked on MGL medium (for $1 \mathrm{~L}$ : $5 \mathrm{~g}$ tryptone, $2.5 \mathrm{~g}$ yeast extract, $5 \mathrm{~g} \mathrm{NaCl}$, 5 g mannitol, $0.1 \mathrm{~g} \mathrm{MgSO}_{4}, 0.25 \mathrm{~g} \mathrm{~K}_{2} \mathrm{HPO}_{4}, 1.2 \mathrm{~g}$ glutamic acid, $\mathrm{pH}$ to 7.2 with $1 \mathrm{M} \mathrm{NaOH}$, solidify with $15 \mathrm{~g}$ agar) containing selection $\left(100 \mu \mathrm{g} \mathrm{mL} \mathrm{m}^{-1}\right.$ carbinicillin and $100 \mu \mathrm{g}$ $\mathrm{mL}^{-1}$ spectinomycin) and incubated at $\sim 28-30^{\circ} \mathrm{C}$ for 2 days prior to co-cultivation. Agrobacterium was scraped from MGL medium plates, suspended in sterile minimal liquid BCIM (for $1 \mathrm{~L}$ : $4.43 \mathrm{~g}$ LS salts with vitamins, $30 \mathrm{~g}$ sucrose, pH 5.8 with $0.1 \mathrm{M} \mathrm{KOH}$ ) containing freshly prepared acetosyringone (stock solution of $200 \mathrm{mM}$ in DMSO) at a final concentration of $200 \mu \mathrm{M}$ and the $\mathrm{OD}_{600 \mathrm{~nm}}$ adjusted to 0.6 . Immediately prior to addition of callus, $10 \mu \mathrm{L}$ of a $10 \%(\mathrm{w} / \mathrm{v})$ Pluronic F68 (in water; sterile filtered) and $0.5 \mu \mathrm{L}$ of $5 \mathrm{mg} \mathrm{mL}^{-1} 2,4-\mathrm{D}$ per $\mathrm{mL}$ Agrobacterium-suspension was added. Callus was incubated $5 \mathrm{~min}$ in Agrobacterium-suspension, followed by decanting of excess solution and transfer of callus to sterile Whatman $3 \mathrm{M}$ filter 
paper disks in petri dishes. Excess Agrobacterium-containing solution was removed by two changes of filter paper disks and calli were allowed to air dry for $\sim 10 \mathrm{~min}$ (total time from start of co-cultivation to plate sealing is $\sim 15 \mathrm{~min}$ ). Plates were capped, sealed with parafilm, and incubated $\sim 22^{\circ} \mathrm{C}$ in the dark (the plate stack was wrapped in $\mathrm{Al}$ foil). After 3 days, calli were transferred to modified BCIM selection medium [BCIM ${ }^{\text {par,mer; }}$ for $1 \mathrm{~L}$ : $4.43 \mathrm{~g}$ LS salts with vitamins, $30 \mathrm{~g}$ sucrose, $1 \mathrm{~mL}$ $0.6 \mathrm{mg} \mathrm{mL}^{-1} \mathrm{CuSO}_{4}$, pH 5.8 with $0.1 \mathrm{M} \mathrm{KOH}, 6 \mathrm{~g}$ Phytoblend (Caisson Labs), autoclaved, then $100 \mu \mathrm{g} \mathrm{mL} \mathrm{m}^{-1}$ paromomycin (PhytoTechnology Laboratories, Shawnee Mission, KS, USA; Guerche et al., 1987; Torbert et al., 1995) and $25 \mu \mathrm{g} \mathrm{mL}{ }^{-1}$ meropenem (I.V. veterinarian-grade; Ogawa et al., 2008) were added (both from 1000x filter-sterilized stocks in water stored at $\left.-20^{\circ} \mathrm{C}\right)$ ], plates were sealed with parafilm and allowed to incubate for 1 week at $28^{\circ} \mathrm{C}$ in the dark. After 1 week, viable callus regions were transferred onto fresh $\mathrm{BCIM}^{\text {par,mer }}$ medium and grown for an additional $2-3$ weeks at $28^{\circ} \mathrm{C}$ in the dark. Viable callus was transferred to Brachypodium plant regeneration selection medium (BRMpar,mer; for $1 \mathrm{~L}$ : $4.43 \mathrm{~g}$ LS salts with vitamins, $30 \mathrm{~g}$ maltose, $\mathrm{pH} 5.8$ with $0.1 \mathrm{M} \mathrm{KOH}, 6 \mathrm{~g}$ Phytoblend; autoclaved, then $200 \mu \mathrm{L}$ of $1 \mathrm{mg} \mathrm{mL}^{-1}$ kinetin, $100 \mu \mathrm{g} \mathrm{mL}^{-1}$ paromomycin, and $25 \mu \mathrm{g} \mathrm{mL}^{-1}$ meropenem were added prior to solidifying). Plantlets were regenerated over 2-4 weeks of incubation at $\sim 24^{\circ} \mathrm{C}$ under a $14 \mathrm{~h}, \sim 40 \mu \mathrm{mol}$ photons $\mathrm{s}^{-1}$ $\mathrm{m}^{-2}$ (cool-white fluorescent light) day/10 h night cycle. Plantlets were transferred to solid MS medium (for $1 \mathrm{~L}: 4.42 \mathrm{~g}$ MS salts with vitamins, $30 \mathrm{~g}$ sucrose, $\mathrm{pH}$ to 5.7 with $0.1 \mathrm{M} \mathrm{KOH}$, $6 \mathrm{~g}$ Phytoblend; autoclaved) in magenta boxes and allowed to form roots over 2-4 weeks of incubation at $\sim 24^{\circ} \mathrm{C}$ under a $14 \mathrm{~h}, \sim 40 \mu \mathrm{mol}$ photons $\mathrm{s}^{-1} \mathrm{~m}^{-2}$ (cool-white fluorescent light) day/10 h night cycle. Plants with roots were transplanted to soil and grown to maturity in a Conviron (Pembina, ND, USA) E15 growth chamber maintained at $24^{\circ} \mathrm{C}$ with a $20 \mathrm{~h}$ light- $4 \mathrm{~h}$ dark light-cycle with an average cool-white fluorescent light photon flux of $180 \mu \mathrm{mol} \mathrm{s}^{-1} \mathrm{~m}^{-2}$.

\section{Transgenic Plant Screening}

Leaf genomic DNA (gDNA) was isolated based on the procedure of Marita et al. (2014). Multiplexed PCR screening of plants for the neomycin phosphotransferase II plant-selection marker and a general gDNA marker, gRGP3, was performed using primers RH196, RH197, RH164, and RH177.

From select transgene-positive plants ( $\mathrm{BCHH}$ developmental stage range 57-61; Hack et al., 1992; Hong et al., 2011; Rancour et al., 2012), $70 \mathrm{mg}$ of fresh-weight leaf tissue was harvested, collected into a capped 2-mL bead-beater tubes containing two $4 \mathrm{~mm}$ acid-washed glass beads, and snap-frozen in liquid nitrogen. Frozen tissue was pulverized by bead-beating and CWs was isolated using a scaled-down procedure based on Rancour et al. (2012). Isolated CWs ( $5 \mathrm{mg}$ ) were subjected to scaled-down $\mathrm{H}_{2} \mathrm{SO}_{4}$-hydrolysis, alditol actetate derivatization, and GLC-FID analysis procedure based on Rancour et al. (2012). CW Glc, Xyl, and Ara content was determined, relative molar ratios were calculated, and all were used to identify plants with altered CW composition (Supplementary Table S5).

\section{Plant Growth and Bulk Tissue Harvest}

All soil-grown plants were grown in environment-controlled growth chambers as described before (Rancour et al., 2012).

RNAi-RGP1 $\mathrm{T}_{1}$ plants were grown to seed fill stage $(\mathrm{BBCH}$ 69-75) and then organs were harvested, sorted, frozen in liquid nitrogen, and stored at $-80^{\circ} \mathrm{C}$. The organs collected included (1) leaf blades and (2) leaf-sheath and stem. Organs of six plants from individual transgenic-events were pooled. All tissue was freezer-milled as described (Rancour et al., 2012).

\section{Quantitative Real-Time PCR Analysis}

Primer design for nucleotide-sugar interconverting enzyme genes was performed with online software as indicated from either (1) Roche Universal ProbeLibrary Assay Design Center ${ }^{1}$ (site link as of September 10, 2013) using default parameters, (2) QuantPrime ${ }^{2}$ (Arvidsson et al., 2008) or (3) Primer-Blast software (Ye et al., 2012) at the NCBI. Primer sequences RH179 and RH180 for Brachypodium UBC18, an identified gene expression-control (Hong et al., 2008), were designed using the Roche software (above). Tissue- and plant linespecific first-strand cDNA was used for quantitative real-time PCR using either SYBR green master mix (Applied Biosystems, Carlsbad, CA, USA) or Bullseye EvaGreen qPCR 2X master mix with ROX (MidSci, St. Louis, MO, USA) based on previous methods (Sullivan, 2009; Marita et al., 2014). Reactions were run using an ABI 7300 Real-Time PCR System using the following conditions: $10 \mathrm{~min}$ denaturation at $95^{\circ} \mathrm{C}, 45$ cycles of $95^{\circ} \mathrm{C}$ for $10 \mathrm{~s}$ and $58^{\circ} \mathrm{C}$ for $1.5 \mathrm{~min}$, followed by amplification product dissociation analysis. Real-time PCR data was analyzed using the LinRegPCR method (Ramakers et al., 2003) and software available at http://www.hartfaalcentrum.nl/index.php? main $\$=\$$ files\&sub $\$=\$$ LinRegPCR (as of July 23, 2013). $\mathrm{N}_{0}$ values for individual reactions run in triplicate were determined and arithmetic means were used to calculate relative expression ratios and SD for target gene to UBC18 expression for the indicated plant organs.

\section{Large-Scale CW Isolation}

Starch-free CW preparations from frozen, homogenized Brachypodium organs were made as described (Rancour et al., 2012).

\section{Large-Scale CW Analysis}

Total CW carbohydrate (uronosyls and neutral sugars) was determined using a scaled-down procedure based on Rancour et al. (2012). Isolated CWs ( $\sim 6 \mathrm{mg}$ ) were subjected to $\mathrm{H}_{2} \mathrm{SO}_{4}{ }^{-}$ hydrolysis.

The sequential analysis of CW ester- and ether-linked phenolic moieties was performed as described (Grabber et al., 1995; Hatfield et al., 2009; Rancour et al., 2012; Marita et al., 2014). Approximately $20 \mathrm{mg}$ of dried CW material per sample was used for analysis. FA dimers (diferulic acid, DFA) presented

${ }^{1}$ www.roche-applied-science.com/webapp/wcs/stores/servlet/CategoryDisplay? catalogId $=10001 \&$ tab $=$ Assay + Design + Center\&identifier $=$ Universal + Probe + Library \&langId=-1

${ }^{2}$ http://www.quantprime.de/main.php?page $=$ home 
represent the sum of areas of identified peaks corresponding to 8-8'-DFA, 8-5' -DFA 8-O-4' $4^{\prime}$-DFA, 8-5'-DFA (benzofuran), 5-5' -DFA, and 8-5' -DFA (decarboxylated). Ester- and etherlinked phenolics were identified and quantified as trimethylsilane derivatives (40 $\mu \mathrm{L}$ TMSI, Pierce and $10 \mu \mathrm{L}$ pyridine) by GLCFID (HP6890) on a ZB-5ms column (Phenomenex, Zebron $25 \mathrm{~m} \times 0.25 \mathrm{~mm}, 0.25 \mu \mathrm{m}$ film). The GLC conditions were: injector $315^{\circ} \mathrm{C}$, detector $300^{\circ} \mathrm{C}$, and a temperature program of $220^{\circ} \mathrm{C} 1 \mathrm{~min}, 4^{\circ} \mathrm{C} \mathrm{m^{-1 }}$ to $248^{\circ} \mathrm{C}$ held $1 \mathrm{~min}$, followed by $30^{\circ} \mathrm{C} \mathrm{min}^{-1}$ to $300^{\circ} \mathrm{C}$ before holding for $16 \mathrm{~min}$. All GC temperature programs were run at 20 psi constant pressure and a split ratio 35:1. Periodic validation of sample peak identifications were performed by GLC-MS. CW preparations were analyzed in duplicate and data was compiled according to genotype and tissue source.

The CW lignin concentration was determined using the modified acetyl bromide method of Hatfield et al. as before (Hatfield et al., 1999a; Fukushima and Hatfield, 2001; Rancour et al., 2012).

Gel-state 2D NMR was performed as described (Marita et al., 2014).

\section{FA-Ara and pCA-Ara Analysis}

Analysis of ferulate (FA)- and $p$-coumarate ( $p$ CA)-linked Ara was performed based on adaptation to the method presented in Marita et al. (2003). CW samples ( $10 \mathrm{mg})$ were hydrolyzed in $2 \mathrm{~mL} 0.1 \mathrm{M}$ trifluoroacetic acid (TFA) for $1 \mathrm{~h}$ at $100^{\circ} \mathrm{C}$. $\mathrm{CW}$ residues were separated from hydrolysates by centrifugation. Supernatants were removed and filtered through $1 \mu \mathrm{m}$ glass-fiber (Acrodisc $^{\circledR} 25 \mathrm{~mm}$ ) syringe filter into to new tubes. CW residues

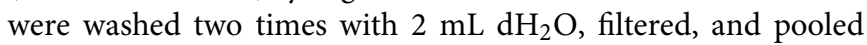
with the original supernatant. UV-Vis absorption spectra (of 1:10 dilution; scan $240-450 \mathrm{~nm}$ ) were taken. The pooled soluble fractions were passed through conditioned and equilibrated C18 columns (Supelco ENVI-18, $3 \mathrm{~mL}$ ). Pooled unbound and column wash (with $0.033 \mathrm{M}$ TFA) material had UV-Vis spectra taken (as above) to verify binding of phenolics. Phenoliccontaining compounds were eluted with $100 \%$ methanol. Internal standards of 2-hydroxycinnamic acid and 5-5-diferulate (50 $\mu \mathrm{g}$ each; stocks: $1 \mathrm{mg} \mathrm{mL}^{-1}$ in $95 \%$ ethanol) were added and samples dried with a stream of filtered air. Phenolic-Araand phenolic-compounds were identified and quantified as trimethylsilane derivatives [40 $\mu \mathrm{L}$ TMSI (Thermo-Fisher) and $10 \mu \mathrm{L}$ pyridine; incubated $30 \mathrm{~min}$ at $55^{\circ} \mathrm{C}$ ] using GLC-MS (Shimadzu GCMS-QP2010) with a ZB-1 column (Phenomenex; $30 \mathrm{~m} \times 0.25 \mathrm{~mm} \times 0.25 \mu \mathrm{m}$ film). The GLC conditions were injector $315^{\circ} \mathrm{C}$ and a temperature program of $200^{\circ} \mathrm{C}$ for $1 \mathrm{~min}$, $4^{\circ} \mathrm{C} \mathrm{min}^{-1}$ to $248^{\circ} \mathrm{C}$, hold $1 \mathrm{~min}$ at $248^{\circ} \mathrm{C}, 30^{\circ} \mathrm{C} \mathrm{min}^{-1}$ to $300^{\circ} \mathrm{C}$ and hold for $16 \mathrm{~min}$. Conditions were run at constant pressure of 16 psi. Sample split ratio was 100 . The MS data collection was in negative mode with scan speed of 1666 , event time of $0.5 \mathrm{~s}, \mathrm{~m} / z$ scan range of 50 to 750 , and acquisition occurring from 1.55 to $31 \mathrm{~min}$ during the run. Quantitative determinations were made from integration of total ion-count chromatogram peaks with corresponding $m / z$ content including FA-Ara-TMS $(614,599)$, pCA-Ara-TMS (584, 569), FA-TMS (338), pCA-TMS (308), and internal standards 2-OH-TMS (308) and FA-dimer-TMS (616).
Standards of FA, pCA, and FA-Ara (Hatfield et al., 1991) were used to verify product identification. All samples were analyzed in duplicate.

\section{Cell Wall Digestibility Xylanase-Treatment}

Cell wall samples $(\sim 5 \mathrm{mg})$ were suspended in buffer $(30 \mathrm{mM}$ citrate/ $\left.\mathrm{NaOH} \mathrm{pH} 4.5,0.01 \%(\mathrm{w} / \mathrm{v}) \mathrm{NaN}_{3}\right)$ containing $2 \mathrm{U}$ $\mathrm{ml}^{-1}$ xylanase (Thermomyces lanuginosus endo-1,4- $ß$-xylanase; Sigma-Aldrich, St. Louis, MO, USA) for a total reaction volume of $0.5 \mathrm{~mL}$. The reaction was incubated $24 \mathrm{~h}$ at $37^{\circ} \mathrm{C}$. Particulate material was pelleted by centrifugation $\left(10 \mathrm{~min}, 20 \mathrm{~K} \times g, \sim 24^{\circ} \mathrm{C}\right)$ and the debris-free supernatant was transferred to new tubes. Total sugar release was assayed in a microtiter-plate format according to Masuko et al. (2005) using Glc for a standard. Sample absorbance at $490 \mathrm{~nm}$ was measured using a Synergy HT Multi-Mode Microplate Reader (BioTek, Winooski, VT, USA). Reactions lacking the addition of CW were used for background absorbance correction. All digestions were preformed in triplicate with sugar assay analytical duplicates for digest products. Glc standards were measured in triplicate over a range of 0 to $3 \mathrm{mM}$ $(0,0.75,1.5,2.25$, and $3 \mathrm{mM})$ resulting in a linear response and an $r^{2}$ value of 0.994 .

\section{Accelerase 1000-Treatment}

Cell wall samples were subjected to Accelerase 1000 (Genencor) enzyme hydrolysis within the CW hydrolysis analytical platform of the Great Lakes Bioenergy Research Center (Michigan State University, East Lansing, MI, USA) based on Santoro et al. (2010). $\mathrm{CW}$ material was subjected to a $6.25 \mathrm{mM} \mathrm{NaOH}$ pretreatment before enzyme hydrolysis. Glc and pentose release was assessed according to facility protocols. Four CW samples per genotype were analyzed in quadruplicate for each sugar class $(n=16)$.

\section{Calculations and Statistics}

Calculations were performed using Microsoft Excel software. One-way ANOVA statistical analysis with a post hoc Tukey test (alpha of 0.05 or 0.01 , as indicated) was performed using GraphPad Prism 5.0F software.

\section{Results}

Using predicted amino acid sequences for known Arabidopsis, rice, and maize enzyme homologs (Delgado et al., 1998; Harper and Bar-Peled, 2002; Burget et al., 2003; Suzuki et al., 2003, 2004; Karkonen et al., 2005; Pattathil et al., 2005; Klinghammer and Tenhaken, 2007; Konishi et al., 2007; Rautengarten et al., 2011; Reboul et al., 2011; Yin et al., 2011), TBLASTN searches (Madden, 2013) of the B. distachyon $\mathrm{Bd} 21$ genome sequence (International Brachypodium Initiative, 2010) were performed to identify Brachypodium homologs. Putative candidate protein sequences were obtained and sequence alignments and phylogenetic analysis were performed for UGD (Supplementary Figure S1), UXS (Supplementary Figures S2 and S3), UXE (Supplementary Figure S4), RGP/UAM (Supplementary Figure S5), and AXS (Supplementary Figure S6). 
The results indicate the Brachypodium genome contains putative genes encoding at least three UGD, six UXS, three UXE, four RGP, and a single AXS gene homolog (Table 1).

Cell wall composition analysis of $B$. distachyon aerial tissues at different stages of plant maturation was performed to provide a comparative bench-mark for using Brachypodium as a C3 forage grass model system (Rancour et al., 2012). RNA-seq was performed on RNA isolated from the eight Bd21-3 tissues analyzed in Rancour et al. (2012). The RNA-seq samples included (1) 12-day seedling leaf blades, (2) 12-day seedling pooled sheaths/stems, expanding stage (3) leaf blades, (4) sheaths and (5) stems, and mature stage (6) leaf blades, (7) sheaths, and (8) stems. Total gene expression profiles were determined to allow for comparative analysis with $\mathrm{CW}$ composition phenotypes and data for the UDP-sugar interconversion pathway members are presented (Figure 1). RNA-seq data for UDPsugar interconversion pathway encoding genes indicated that UXS1 (Bradilg66230) was not expressed in the tissues analyzed. In addition, RGP3 (Bradi2g50660) expression was present in sheath and stem samples but not leaf blade samples regardless of developmental stage.

Gene expression of UGD1 (Bradilg08120), UXS6 (Bradilg66440), and RGP1 (Bradilg15050) was consistently high throughout development and could be categorized in the top $1 \%$ of most-abundant genes expressed (Figure 1B). In addition, many of the remaining pathway encoding genes, including UGD2, UGD3, UXS2, UXS4, UXS5, RGP2, RGP4, and $A X S$, could be included in the top $10 \%$ of genes expressed in many samples analyzed. These data indicate that expression of genes encoding enzymes of the UDP-sugar interconversion pathway is relatively high in tissues that have extensive $\mathrm{CW}$ production and modification.

The UDP-sugar interconversion pathway is thought to provide the primary substrates for hemicellulose and pectin biosynthesis (Reiter, 2008; Bar-Peled and O'Neill, 2011; Yin et al., 2011; Atmodjo et al., 2013). We sought to test the hypothesis that targeted manipulation of expression of UDPsugar interconversion pathway encoding genes could influence substrate availability, lead to changes in CW carbohydrate composition, and influence $\mathrm{CW}$ digestibility in grasses. Our goal was to change the $\mathrm{CW}$ characteristics with little affect on plant stature and development. To test this, cDNAs corresponding to a number of UDP-sugar interconversion pathway encoding genes were cloned (Supplementary Figure S7 and Table S3), constitutive expression (OX) and hairpin-RNAi constructs were made, and those binary constructs were used to transform
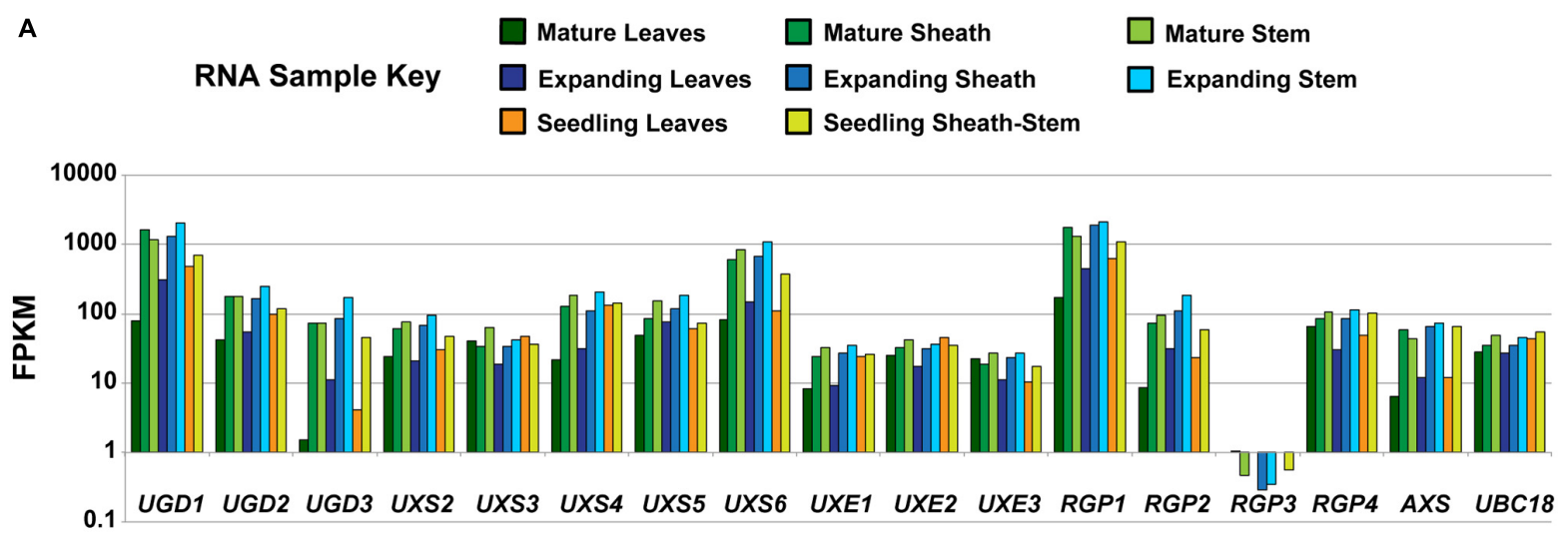

B

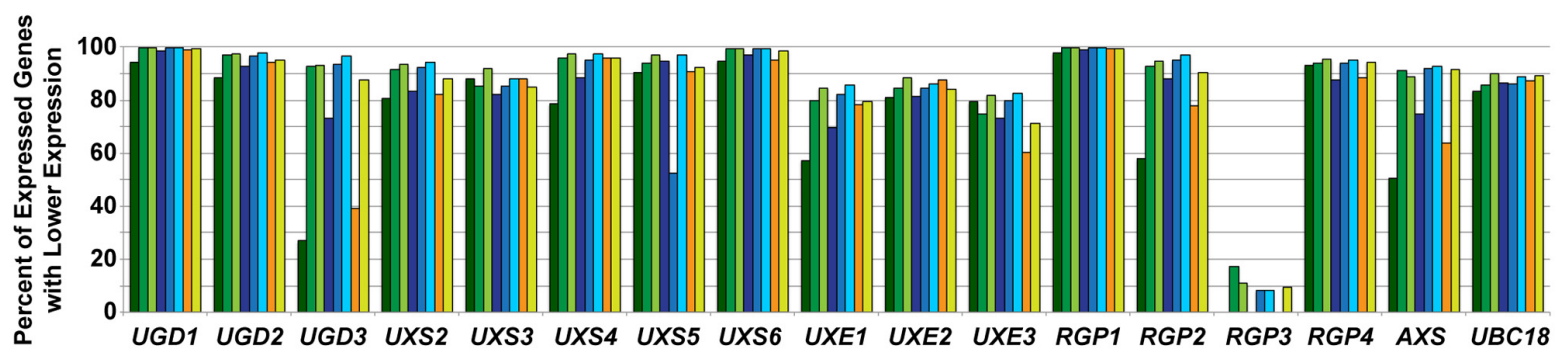

Gene

FIGURE 1 | Analysis of developmental expression of genes encoding UDP-sugar inter-conversion pathway enzymes in Brachypodium distachyon. (A) Analysis of RNA from tissues previously characterized in Rancour et al. (2012) by RNA-seq for genes encoding UDP-sugar

inter-conversion pathway enzymes and the real-time PCR amplification control (UBC18). The samples represent a developmental series of distinct tissues.
A key is given. Data are log base 10 scale of fragments per kilobase of transcript per million fragments mapped (FPKM). (B) Expression ranking for genes encoding UDP-sugar inter-conversion pathway enzymes and the real-time PCR amplification control. Ranking values represent the percent of expressed genes with FPKM values lower than the indicated gene for the given tissue. For RGP3, expression in leaf blades at all developmental stages was not detected. 
B. distachyon $\mathrm{Bd} 21-3$ (Table 2). Large cDNA gene segments were used for the RNAi-constructs to take advantage of homologous regions between gene family members for potential wholefamily suppression (Wesley et al., 2001). Additionally, cDNAs used for RNAi-constructs had select deletions corresponding to regions targeted by real-time PCR primers to allow for assessment of endogenous gene expression in a background where the RNAi-construct is being expressed (Supplementary Table S4). Transformation of the constructs resulted in numerous independent $\mathrm{T}_{0}$-lines that were screened (Table 2) for leaf $\mathrm{CW}$

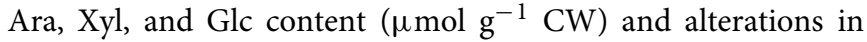
Ara:Xyl and Xyl:Glc ratios (Supplementary Table S5). A threshold of two standard deviations from wild-type and empty-vector transgenic plants was used to mark the significance of the value changes observed. Based on these parameters, RNAi-RGP1 plant lines had significant changes from wild-type values including decreased CW Ara content and decreases in Ara:Xyl ratios. Therefore, we sought to further characterize gene expression and the CW phenotype of the Brachypodium RNAi-RGP1 plant lines.

To ensure sufficient materials for complete analysis, aerial organs from independent-event $\mathrm{T}_{1}$-plants for five $R N A i$-RGP1 (RNAi-RGP1_371,373, 382, 384, and 393) and two emptyvector control (EVC_173 and 175) lines were harvested from six plants each, pooled, and processed in parallel. In parallel, wild-type $\mathrm{Bd} 21-3$ plants were grown and harvested at the same time as the $T_{1}$ transgenic plants. Leaf blades (leaf) and leaf sheaths and stems (sheath/stem) were harvested, pooled

TABLE 2 | Summary of transgenic plants made in this study.

\begin{tabular}{|c|c|c|c|c|}
\hline Target gene & $\begin{array}{l}\text { Construct } \\
\text { type }\end{array}$ & $\begin{array}{l}\text { TOTAL } \\
\text { Events } \\
\text { generated }\end{array}$ & $\begin{array}{l}\text { CW CHO } \\
\text { Events } \\
\text { screened }\end{array}$ & $\begin{array}{l}\text { Plants } \\
\text { screened }\end{array}$ \\
\hline \multirow[t]{2}{*}{ UGD1 } & OX & 17 & 12 & 24 \\
\hline & $\mathrm{RNAi}$ & 16 & 13 & 26 \\
\hline UGD2 & RNAi & 17 & 11 & 21 \\
\hline \multirow[t]{2}{*}{ UXS2 } & OX & 4 & 4 & 8 \\
\hline & RNAi & 25 & 21 & 41 \\
\hline UXS4 & RNAi & 10 & 0 & 0 \\
\hline \multirow[t]{2}{*}{ UXS6 } & OX & 7 & 7 & 14 \\
\hline & RNAi & 12 & 8 & 16 \\
\hline \multirow[t]{2}{*}{ UXE1 } & OX & 6 & 4 & 8 \\
\hline & $\mathrm{RNAi}$ & 21 & 17 & 34 \\
\hline UXE2 & $\mathrm{RNAi}$ & 36 & 20 & 34 \\
\hline RGP1 & $\mathrm{RNAi}$ & 21 & 13 & 25 \\
\hline RGP2 & RNAi & 34 & 10 & 14 \\
\hline RGP4 & RNAi & 9 & 0 & 0 \\
\hline \multirow[t]{2}{*}{ AXS } & OX & 4 & 4 & 8 \\
\hline & RNAi & 43 & 27 & 45 \\
\hline Ubip::GusPlus & OX & 21 & 3 & 6 \\
\hline Empty vector control & OX & 6 & 6 & 12 \\
\hline
\end{tabular}

Total 309 180 336

Total number of events generated per construct (TOTAL) and the number of subsequent events and plants per event screened for leaf CW carbohydrate (CW $\mathrm{CHO}$ ) alterations. according to plant-line, and used for subsequent analysis. Images of representative plants at harvest were taken (Figure 2). The morphology of RNAi-lines was comparable to empty vector control lines. The stature of RNAi-RGP1_384 and 393 lines were modestly shorter and more uniform. For example, stem lengths were $24.8 \pm 5.4 \mathrm{~cm}$ (mean $\pm \mathrm{SD} ; n=14$ ) for EVC_175, $22.5 \pm 3.6 \mathrm{~cm}(n=13)$ for RNAi-RGP1_371, and $20.0 \pm 1.6 \mathrm{~cm}$ $(n=16)$ for RNAi-RGP1_384. ANOVA analysis (post hoc Tukey test; alpha $=0.05$ ) indicated the difference between EVC_175 and $R N A i-R G P 1 \_384$ was statistically significant with a height reduction of $19 \%$. Yields of CW from fresh weight tissue were comparable between control and RNAi-RGP1 mutant lines (Supplementary Table S6).

\section{Cell Wall Carbohydrates}

To verify that the CW carbohydrate screening results were heritable, total $\mathrm{CW}$ sugars were analyzed from isolated CWs of leaf and sheath/stem fractions. CWs from leaf (Figure 3A) and sheath/stem (Figure 3B) both exhibited statistically significant decreases in Ara content in four of the five RNAi-RGP1 lines when compared to empty vector control lines and wild-type $\mathrm{Bd} 21-3$ (WT) CWs. The reductions ranged from 27 to $51 \%$ of EVC_173 levels based on numerical mean values. RNAi-RGP1 lines 384 and 393 exhibited the greatest reduction in CW Ara. The CW Ara content of EVC lines and wild-type plants were not statistically different. CW Glc, Xyl, and uronosyl content did not deviate from EVC and WT values (Supplementary Table S7).

The CW molar ratio of Ara to Xyl in grasses is used as an indicator of the relative substitution of the $\beta$-1,4-xylan backbone with Ara subunits. Given that the CW Glc and Xyl did not change in $R N A i-R G P 1$ mutants, the change in leaf (Figure 3C) and sheath/stem (Figure 3D) CW molar ratios of Ara to Xyl reflected the decrease in total CW Ara content. These results indicate that in select $R N A i-R G P 1$ mutant Brachypodium lines, $\mathrm{CW}$ Ara is reduced up to $50 \%$ of control and that this reduction does not alter $\beta$-1,4-xylan content of the CW.

\section{RGP Gene Expression}

Hairpin RNAi methods have been extensively used as a tool to suppress gene expression and function in vivo (Watson et al., 2005). To determine the efficacy of our RNAi-RGP1 construct on the Brachypodium RGP gene family expression, we used relative real-time PCR to assess changes in gene expression (Figure 4). The relative gene-specific expression of RGP1 (Bradilg15050; A and E), RGP2 Bradilg21990; B and F), RGP3 (Bradi2g50660; C and $\mathrm{G}$ ), and RGP4 (Bradi5g24850; D and H) was assessed from leaf (Figures 4A-D) or sheath/stem (Figures 4E-H). We used the BdUBC18 (Bradi4g00660) gene, which encodes ubiquitinconjugating enzyme 18 (Hong et al., 2008), as a reference marker for real-time PCR. The uniformity of expression of BdUBC18 across organs and development was supported in our RNA-seq data (Figure 1A).

RNAi-RPG1 lines 371, 373, 384, and 393 demonstrated significant reductions in $R G P 1$ gene expression throughout the organs analyzed (Figures $4 \mathbf{A}, \mathbf{E}$ ). The data indicate the abundance of target gene $R G P 1$ transcript in $R N A i-R G P 1$ lines was reduced in leaves of line 373 to $17 \%$ and in sheaths/stems in line 393 to 

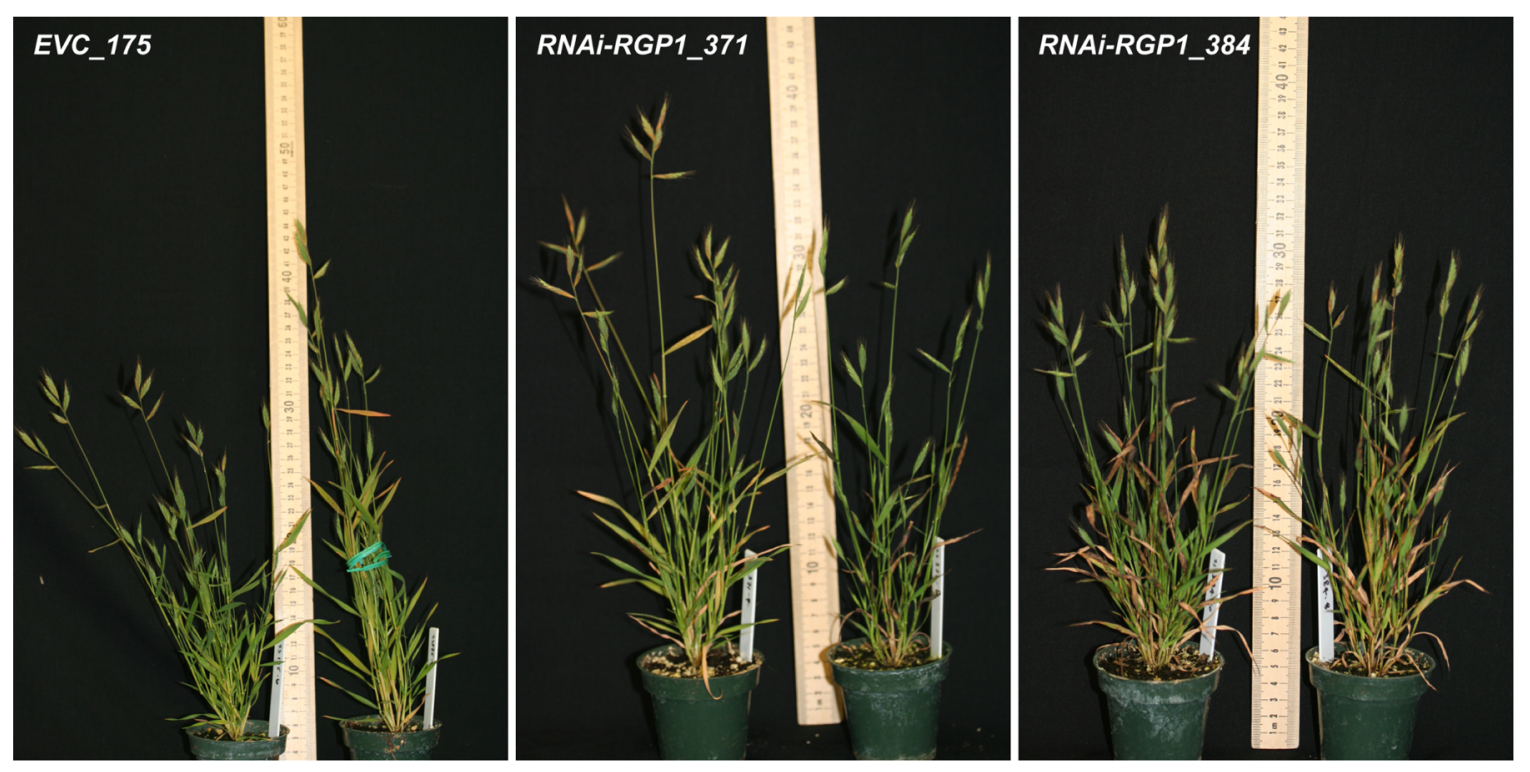

FIGURE 2 | Plant stature of $\mathbf{T}_{\mathbf{1}}$ RNAi -UDP- $\boldsymbol{\beta}$-L-Arap mutase $\boldsymbol{B}$. distachyon lines. Representative plants from $\mathrm{T}_{1}$ transgenic empty-vector control line 175 (EVC_175) and RNAi-RGP1 lines 371 (RNAi-RGP1_371) and 384 (RNAi-RGP1_384) at the time of harvest. Scale stick is in centimeters.

$22 \%$ (relative to control line EVC_173). In line 382, RGP1 geneexpression was modestly reduced in leaves with no reduction detected in sheaths/stems. These data are consistent with CW analysis (Figures 3A,B) where lines 371, 373, 384, and 393 all demonstrated reductions in Ara abundance, whereas line 382 did not. As expected these data indicate a strong correlation between RGP1 gene expression and CW Ara abundance with Pearson correlation coefficients of 0.83 and 0.87 for leaves and sheath/stem samples, respectively.

However, based on the design of our RNAi-RGP1 construct through the use of a large cDNA fragment, we were also interested in whether silencing of other RGP gene family members was occurring in our $R N A i-R G P 1$ plants. Predictions of possible off-site targets for our RNAi construct were made using the psRNATarget online tool $^{3}$ (Dai and Zhao, 2011) with default search parameters against the $B$. distachyon transcripts, Phytozome v8.0 option. The results (see Supplementary Table S8) suggested that other $R G P$ gene family members could be targets for our RNAi-RGP1 construct as well. Therefore, using relative real-time PCR, the expression of $R G P 2, R G P 3$, and $R G P 4$ was determined (Figures $\mathbf{4 B}-\mathbf{D}, \mathbf{F}-\mathbf{H}$ ). The real-time PCR results corroborated the RNA-seq data where expression of $R G P 2, R G P 3$, and RGP4 was at least an order of magnitude less than RGP1. The real-time PCR results highlighted that RGP2 and RGP3 expressions also were attenuated consistently in leaf tissue with lines 371, 373, 384, and 393. There was greater variability in the expression of RGP2 and RGP3 in sheaths/stems of control lines and $R N A i-R G P 1$ lines. With $R G P 2$ expression in sheaths/stems, control lines had nearly a $30 \%$ differential in expression.

Large variation in control-line RGP2 expression in sheaths/stems, RNAi-RGP1 lines 384 and 393 exhibited

${ }^{3} \mathrm{http}: / /$ plantgrn.noble.org/psRNATarget/ reductions of near $50 \%$ of the $E V C_{-} 175$ value while lines 371 and 373 did not deviate from control expression levels. With RGP3 expression in sheaths/stems, RNAi-RGP1 lines 371, 373,384 , and 393 did not change from control plant expression levels. Interestingly, expression of $R G P 2$ and $R G P 3$ increased in $R N A i-R G P 1$ line 382 , the line that did not maintain the reduced CW Ara phenotype observed in the $\mathrm{T}_{0}$ stage, but the biological significance is not known. With the expression of RGP4, only one line, RNAi-RGP1_373, had a change in expression with a $25 \%$ reduction in expression in leaf blades. The remaining lines, irrespective of tissue source, did not deviate from control plant expression levels thus calling into question the biological significance of the reduction observed in line 373 .

Considering all of the RGP gene family expression data together, our results indicate that the RNAi-RGP1 construct predominantly influenced expression of RGP1, RGP2, and RGP3 but not RGP4. Expression of RGP1, RGP2, and RGP3 were greatly reduced in leaves from lines $371,373,384$, and 393. In sheaths and stems, our RNAi-RGP1 construct most affected RGP1 expression with a varying affect on RGP2 expression as is evident in lines 371 and 373 versus 384 and 393. When considering gene expression with CW Ara content, it can be argued that RGP1 and RGP2 expression attenuation had the greatest impact on reducing $C W$ Ara levels in our RNAi mutant Brachypodium plants.

\section{Cell Wall Hydroxycinnamates and Crosslinks are Reduced in RNAi-RGP1 Mutant Plants}

The Araf modification of grass xylans provides a site for incorporation of ester-linked hydroxycinnamates into the CW. FA is esterified to the $5^{\prime}$ hydroxyl of Araf and can be involved in (1) FA-dimerization forming inter-xylan crosslinks and (2) providing sites for coupling to lignin polymers (Grabber et al., 


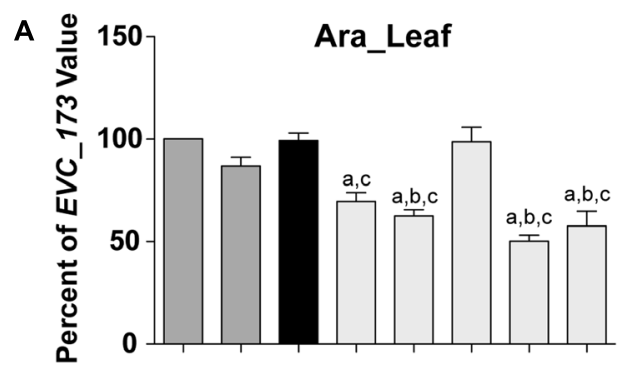

C

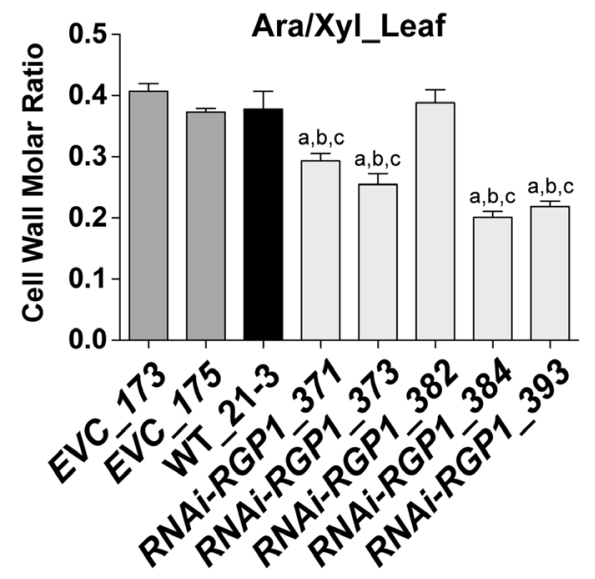

Plant Line

FIGURE 3 | Decreased CW Ara content in RNAi -UDP- $\beta$-L-Arap mutase B. distachyon lines. (A) Leaf blade and (B) leaf sheath/stem normalized CW Ara content of empty-vector control lines (173 and 175), wild-type Bd21-3 (WT_21-3), and RNAi-RGP1 lines (371, 373, 382, 384, and 393) (left to right). All values were normalized with EVC_173 set to $100 \%$. The leaf and sheath/stem EVC_173 values (mean $\pm \mathrm{SEM} ; n=4$ ) were $341.5 \pm 25.4$ and

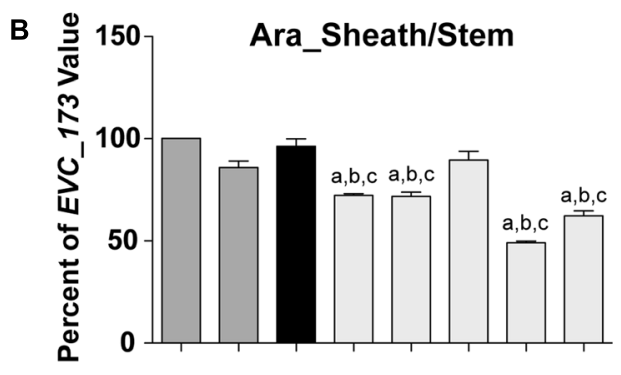

D

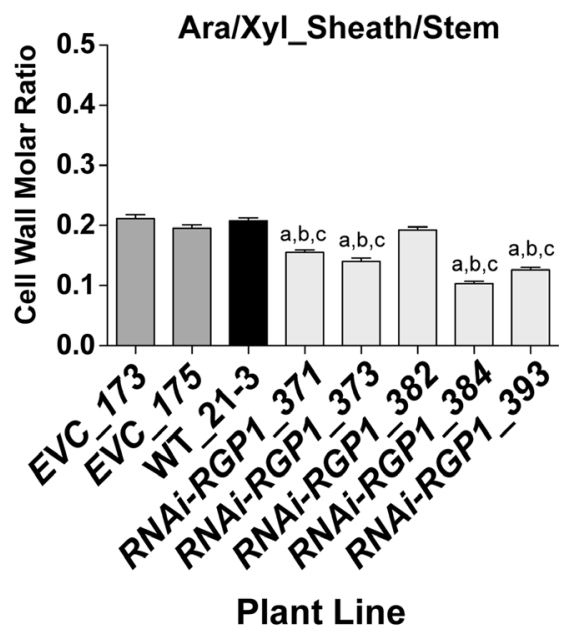

$247.9 \pm 6.8 \mu \mathrm{mol}$ Ara $^{-1}$ CW, respectively. (C) Leaf blade and (D) leaf sheath/stem CW molar ratios of Ara to Xyl of empty-vector control lines (EVC_173 and 175), wild-type Bd21-3 (WT_21-3), and RNAi-RGP1 lines (371, $373,382,384$, and 393). Error bars indicate SEM. ${ }^{a, b, c}$ significantly different from EVC_173, EVC_175, and WT_21-3 values, respectively (ANOVA with post hoc Tukey test, alpha $=0.05$ ).
1995; Hatfield et al., 1999b; de O Buanafina, 2009). FA crosslinking has been shown to negatively correlate with $\mathrm{CW}$ digestibility (Grabber et al., 1998a,b). We sought to determine if reductions in CW Ara resulted in parallel reductions in FA and FA-dimers (Figure 5). As part of our normal analysis platform, $p C A$ were also analyzed. Traditionally, $p \mathrm{CA}$ is thought to be primarily a component of lignin (Grabber, 2005; Hatfield and Marita, 2010).

Cell wall ester-linked FA and FA-dimers were reduced in RNAi-RGP1 mutant lines when compared to controls lines (Figures 5A,B,D,E). Reductions were observed in both leaf and sheath/stem tissues of lines that exhibited reductions in CW Ara. The greatest reduction in FA and FA-dimer values were from lines 384 and 393 that also had the greatest reduction in CW Ara. CW ester-linked FA was reduced to as low as $48 \%$ of control values in line 393 leaves and 44\% of control in sheath/stem of line 384. Likewise, ester-linked FA-dimers were reduced to as low as $39 \%$ of control values in line 393 leaves and $60 \%$ of control in sheaths/stems of line 384. Statistically, these data indicate that ester-linked CW FA and FA-dimers are significantly reduced in $R N A i-R G P 1$ mutant plants.
The abundance of ester-linked CW $p$ CA also decreased in both leaves and sheaths/stems tissues of RNAi-RGP1 mutant plants (Figures $5 \mathrm{C}, \mathbf{F})$. The relative decreases in $p C A$ were less than those measured for FA and FA-dimers. Ester-linked $p$ CA was reduced to as low as $72 \%$ of control values in line 393 leaves and $84 \%$ of control in sheath/stem of line 384 .

Ether-linked hydroxycinnamates are a result of the presence of CW hydroxycinnamates during the oxidative-coupling processes during lignification (Hatfield et al., 1999b; Ralph et al., 2004). Tissue-specific differences were observed on the release of etherlinked monomeric hydroxycinnamates (FA and $p \mathrm{CA}$ ) compared to FA-dimers (Figures 5G-L). In leaves from strong mutant lines 384 and 393, ether-linked monomeric hydroxycinnamate amounts increased relative to control lines but FA-dimers did not show significant change. On the contrary, leaf ether-linked FA-dimers were reduced in the weak RNAi lines 371 and 373. In sheath/stem CWs, ether-linked FA were similar to the esterlinked FA in that strong RNAi-RGP1 lines had the greatest reductions in FA specifically with line 393 down to $75 \%$ of control. Ether-linked $p$ CA values did not change. Ether-linked FA-dimers increased in strong RNAi-RGP1 mutant lines 384 


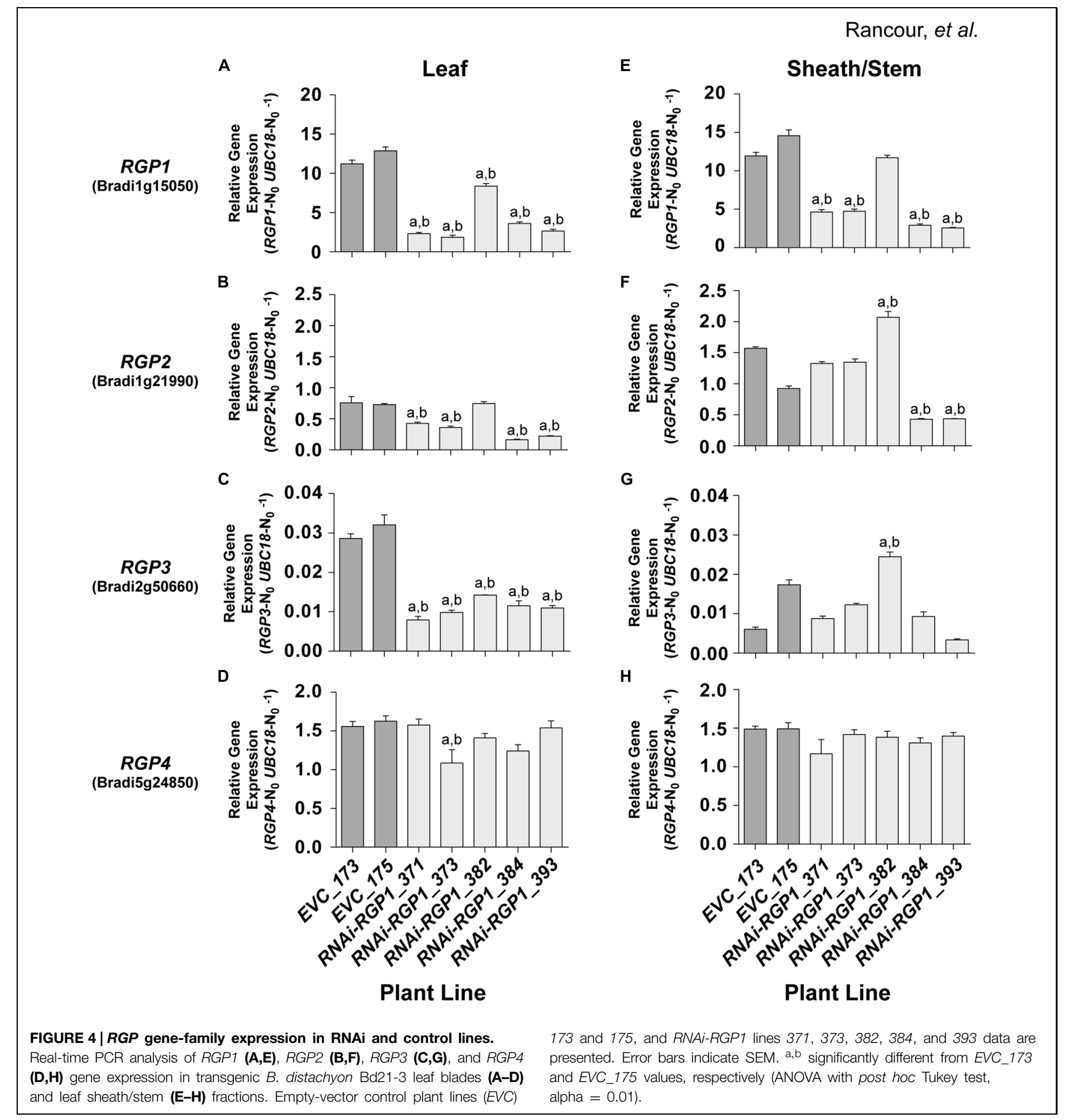

and 393 to values of 150 and $135 \%$ of EVC_173 control value, respectively.

The results from analysis of CW hydroxycinnamates indicate that levels of ester-linked FA, ester-linked FA-dimers, and ester-linked $p C A$ decrease in strong RNAi-RGP1 mutant lines. Current models indicated that FA and FA-dimers are directly coupled to arabinoxylans, however, $p \mathrm{CA}$ is predominantly a component of lignin. Recent work has shown that some of the
CW ester-linked $p$ CA is actually covalently bound to Ara of arabinoxylans in Brachypodium (Petrik et al., 2014). Therefore we developed and used a modified procedure for the analysis of ester-linked FA-Ara and $p$ CA-Ara conjugates (Figure 6). The procedure uses a mild TFA hydrolysis procedure to release the FA-Ara and pCA-Ara moieties and the total hydrolysate is analyzed by GLC-MS with total ion chromatogram outputs (Figure 5E). 


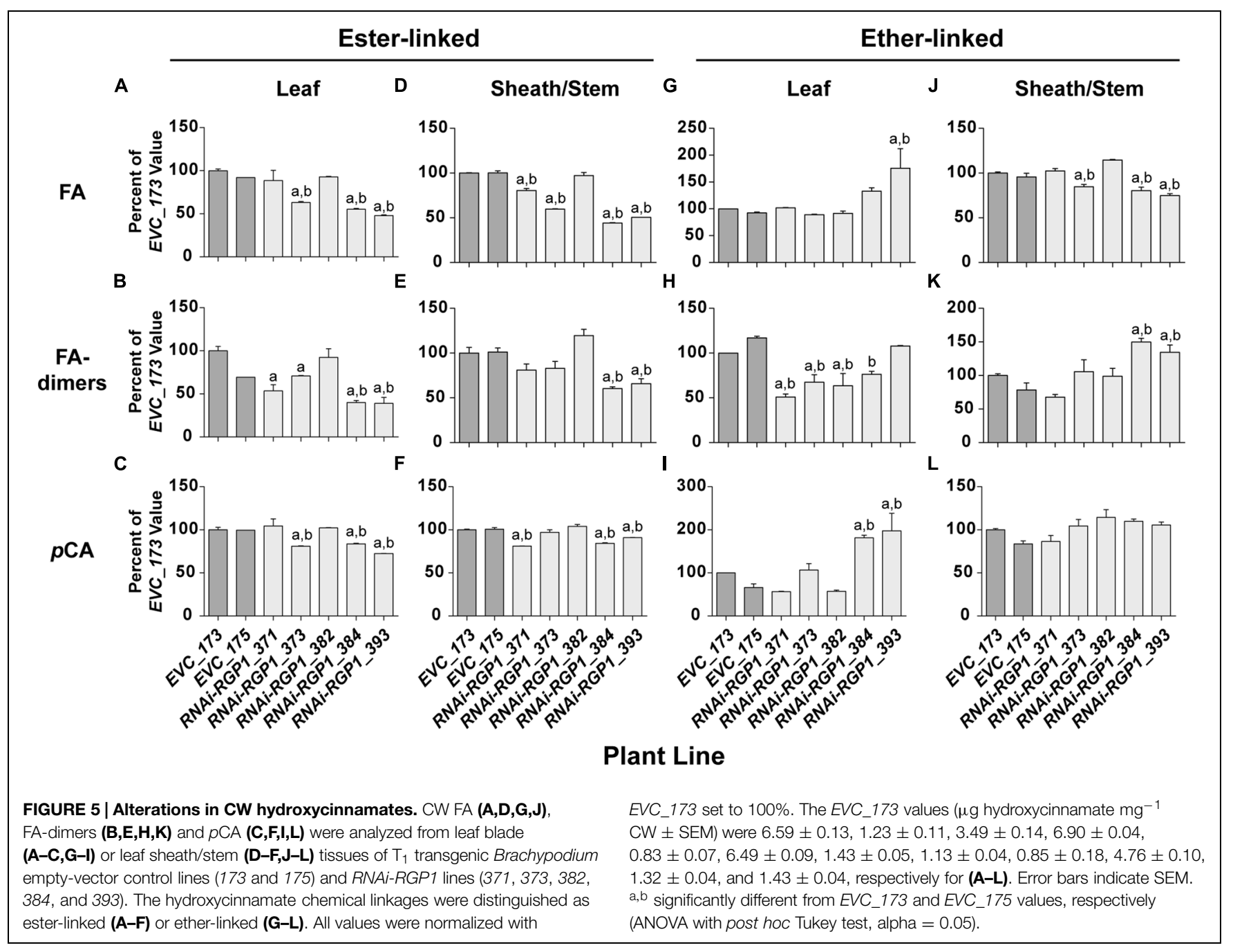

Analysis of CW FA- and pCA-Ara indicated that RNAiRGP1 lines that showed reductions in CW Ara levels exhibited reductions in both FA-Ara (Figures $\mathbf{6 A}, \mathbf{C}$ ) and $p$ CA-Ara (Figures 6B,D) compared to $E V C$-lines. The trends of decreased FA-Ara and $p$ CA-Ara followed relative decreases in ester-linked FA, $p \mathrm{CA}$, and CW Ara abundances. It is expected that FA-Ara reductions would be comparable to the total ester-linked FA reduction assuming that FA-Ara is the sole source of $\mathrm{CW}$ esterlinked FA. However, the proportional reductions in $p$ CA-Ara are much greater than the reductions in total ester-linked $p C A$. For example $p$ CA-Ara was reduced by as much as $60 \%$ in $R N A i-$ RGP1_384 leaves and 76\% in RNAi-RGP1_393 sheaths/stems while the reductions in total ester-linked $p$ CA was only 16 and $28 \%$, respectively. Comparing our data, we determined that $p \mathrm{CA}$ Ara conjugates comprise approximately $50 \%$ of the total esterlinked $p C A$ in $B$. distachyon and that the reduction in ester-linked $p C A$ observed in strong $R N A i-R G P 1$ lines is likely derived from pCA-Ara.

The molar ratio of CW monomeric FA (ester- and etherlinked) to Ara can indicate changes in the modification frequency of Ara by FA. Our data showed only one statistically significant change in the normalized organ-specific CW FA to Ara ratio between RNAi-RGP1 mutants and EVC-lines (Supplementary Figure S8). The only statistically significant difference occurs when comparing sheath/stem CW FA to Ara of EVC_173 to RNAi-RGP1_371 (Supplementary Figure S8B). All remaining comparisons were not statistically significant. Taken in their entirety, the data suggest that the FA substitution frequency on Ara is not directly impacted by the RGPs.

With changes in CW hydroxycinnamates and Ara detected in RNAi-RGP1 lines, we sought to determine if changes occurred in total lignin and lignin composition. Total CW lignin was determined by the acetyl bromide lignin method as described (Fukushima and Hatfield, 2001; Rancour et al., 2012). The lignin concentration was significantly changed only in leaf CWs from RNAi-RGP1_384 and 393 lines where total lignin was increased by 29 and $21 \%$, respectively (Supplementary Figure S9A). The results indicated that no significant differences in total lignin were present between $E V C$ and $R N A i-R G P 1$ lines in sheath/stem tissue (Supplementary Figure S9B).

To determine if lignin composition changes occurred, gelstate 2D NMR analysis of total CWs isolated from WT_21-3 and 


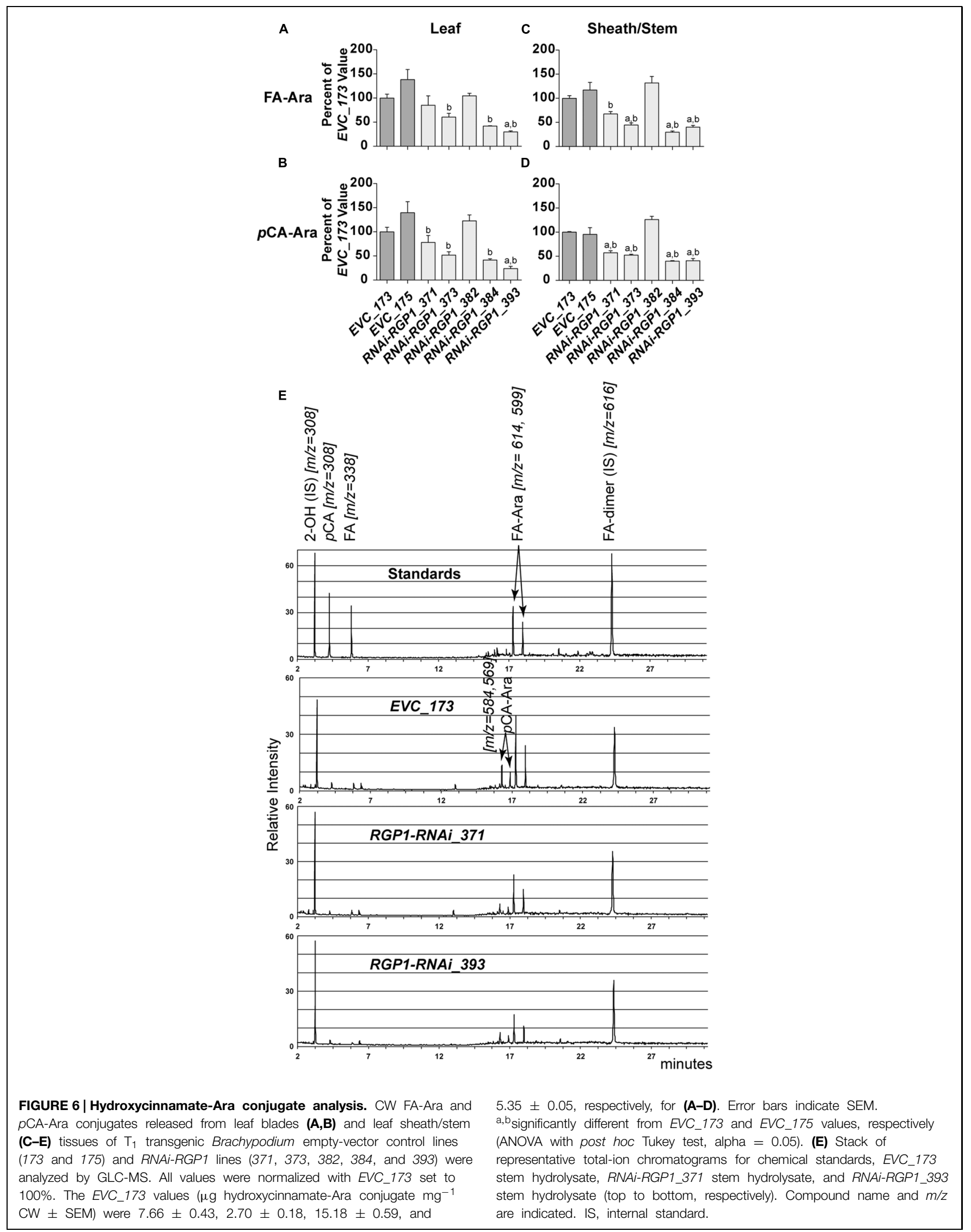


RNAi-RGP1_373 and 393 lines was performed as described (Kim and Ralph, 2010; Marita et al., 2014) to quantify lignin subunit ratios (syringyl to guaiacyl) and the relative syringyl to $p C A$ composition. Reliable quantification of the aromatic unit ratios is dependent on the integrations of well-dispersed 2- and/or 2,6- positions of each aromatic unit. The 2D HSQC experiment performed on the Brachypodium CWs accounts for all of a given phenolic component (all guaiacyl and syringyl units) within the $\mathrm{CW}$. The syringyl to guaiacyl subunit ratios differed modestly in leaves with values of 0.44 for WT_21, 0.48 for RNAi-RGP1_373, and 0.68 for RNAi-RGP1_393. In addition to changes in the syringyl:guaiacyl $(S: G)$ lignin subunit ratio, a modest change in the leaf syringyl:pCA ratio was observed with values of 1.06 for WT_21, 1.66 for RNAi-RGP1_373, and 2.42 for RNAi-RGP1_393. Only among lines with the greatest reduction in $R G P$ expression do we detect changes in total lignin and lignin composition. These lignin alterations appear confined to leaf blade walls but the biological significance is not known. Taken together, reductions in CW hydroxycinnamates and Ara do not correlate with drastic whole-plant alterations in total lignin and lignin composition.

\section{Digestibility of RNAi-RGP1 CWs}

The digestibility of plant biomass is an important feature in forage utilization and bioenergy applications. Numerous factors, including lignin and FA-crosslinking, have been proposed to negatively impact digestibility. With the observed reductions of CW ester-linked hydroxycinnamates, including FA and FAdimers, in our RNAi-RGP1 plants, we sought to determine if these plants had alterations in the enzyme-mediated digestibility characteristics. Firstly, sheath/stem CWs were treated with $T$. lanuginosus endo-1,4- $\beta$-xylanase overnight and total sugar release was measured (Figure 7). Without any pre-treatment of the CWs, we observed increases in released CW carbohydrate

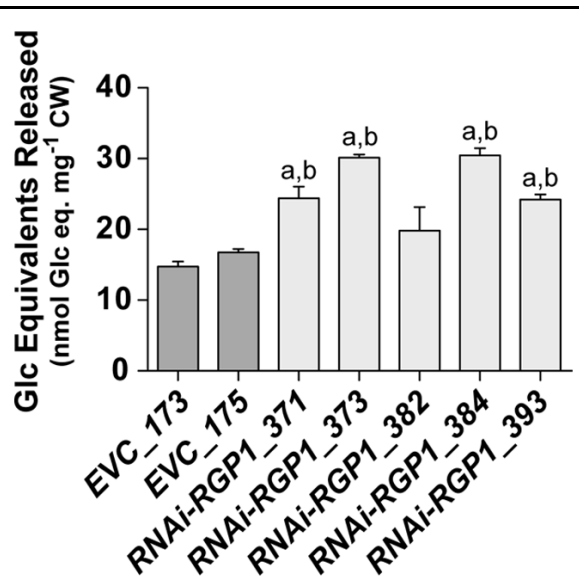

FIGURE 7 | Increased CW digestibility of Ara-deficient mutant B. distachyon with xylanase. Total sugar released from Thernomyces lanuginosus endo-1,4- $\beta$-xylanase-treated sheath/stem CWs of $T_{1}$ transgenic Brachypodium empty-vector control lines (173 and 175) and RNAi-RGP1 lines $(371,373,382,384$, and 393) is presented. Error bars indicate SEM. a,b significantly different from EVC_173 and EVC__175 values, respectively (ANOVA with post hoc Tukey test, alpha $=0.05$ ). of up to twofold from RNAi-RGP1 lines compared to $E V C$-lines. Carbohydrate released from $E V C$-lines was 14.7-16.7 nmol Glc equivalents per $\mathrm{mg} \mathrm{CW}$. The RNAi-RGP1 lines with notable Ara and hydroxycinnamate reductions exhibited carbohydrate release amounts of 24.2-30.5 nmol Glc equivalents per mg CW. These data indicate that reductions of CW-bound Ara and hydoxycinnamates in grasses without changing lignin levels can lead to improved xylan digestibility.

To determine if total CW digestibility was improved with Brachypodium RGP suppression, saccharification was assessed using the Accelerase 1000 enzyme mixture (Santoro et al., 2010) on sheath/stem and leaf CWs based on Santoro et al. (2010) (Figure 8). CW material was pretreated with $6.25 \mathrm{mM} \mathrm{NaOH}$. Release of CW Glc and pentoses were measured and those data are presented. Pentose release from mutant sheath/stem CWs was improved in the weak expressing RNAi-RGP1 mutants 371 and 373 (Figure 8B). RNAi-RGP1 line 373 exhibits an increase of $18 \%$ over $E V C \_173$ control. With the stronger expressing RNAiRGP1 mutant alleles, 384 and 393, apparent sheath stem pentose release was unaffected. Pentose release from leaf CWs was mostly unaffected except for a decrease observed in the strong expressing $R N A i-R G P 1$ line 393 (Figure 8C).

Glucose release from $R N A i-R G P 1 \mathrm{CWs}$ exhibited mixed and unexpected results (Figure 8B,D). Sheath/stem Glc release was not consistently altered across $R N A i-R G P 1$ lines when compared to control lines (Figure 8B). Weak expressing RNAi-RGP1 lines trended with increased Glc release while strong expressing lines showed decreases in Glc release from sheath/stem CWs. Surprisingly, Glc release was reduced significantly from leaf CWs of all RNAi-RGP1 lines (Figure 8D). The reduction in leaf Glc release positively correlated with CW Ara content and the relative reductions in RGP1 and $R G P 2$ gene expression with Pearson correlation coefficients of $0.90,0.78$, and 0.94 , respectively. These data indicate organ-specific effects on CW composition translate to differing consequences on CW digestibility depending on the enzyme treatment being applied.

\section{Discussion}

The acknowledgment of climate change and the need to support the growing global human population's need for food has put high demand on technology development to maximize plant biomass production and utilization for sustainable and renewable sources of food, feed, fiber, and energy (FAO, 2003). To move forward with research to address these needs requires a clear understanding of how processes occur from gene expression to final assembly in a functioning plant. Approaches to improve biomass quality and use-efficiency while not grossly impacting yields are needed.

The plant CW is a complex mixture of carbohydrates, aromatic-compounds, and protein that is critical for plant form and function but is yet poorly understood in how it is assembled and managed throughout plant development. The content of the plant CW suggests it is a metabolic sink for cell carbohydrate. It is this carbohydrate that is most useful in terms of feed, fiber, and bioenergy and its utilization is dependent upon 


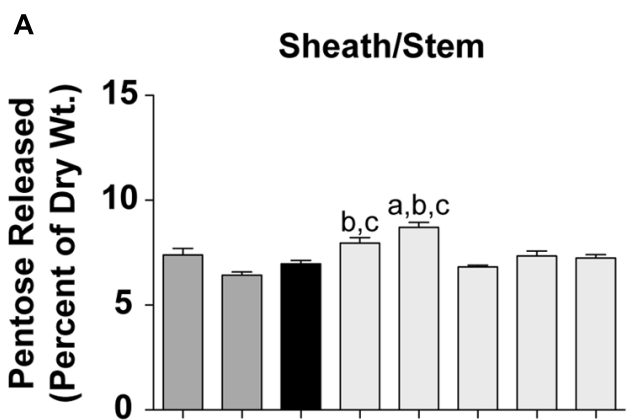

B

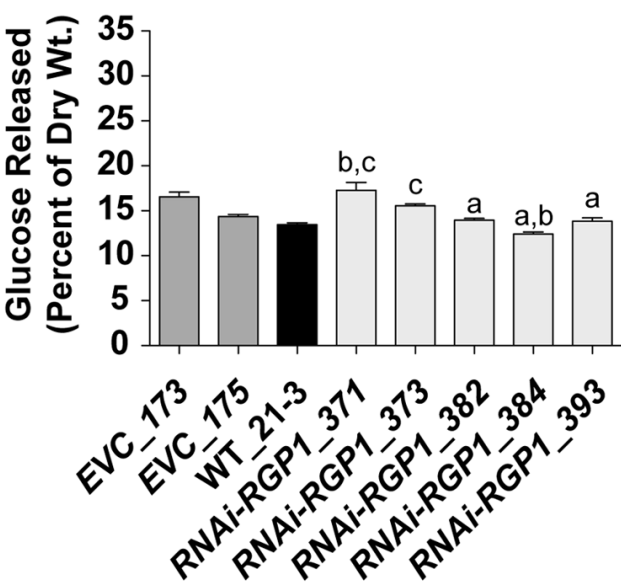

C

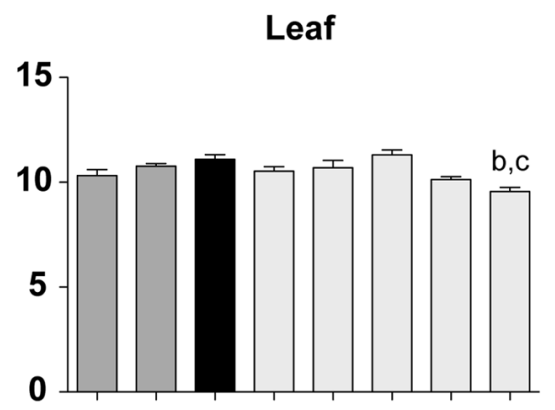

D

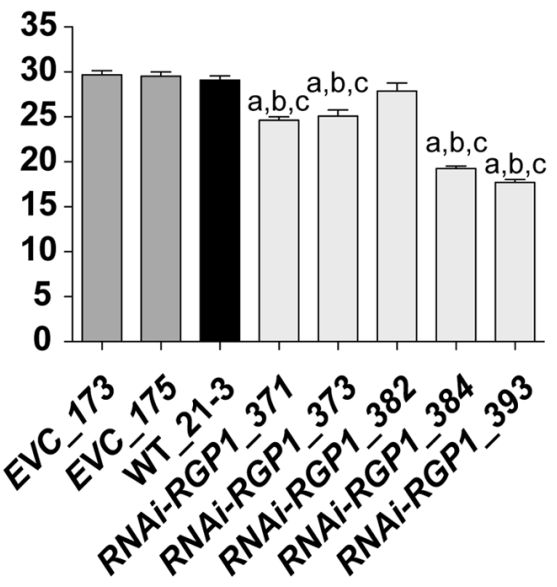

FIGURE 8 | Saccharification of Ara-deficient mutant B. distachyon CWs with Accelerase 1000 enzyme mix. Pentose $(A, C)$ and Glc (B,D) released from Accelerase 1000-treated sheath/stem (A,B) and leaf (C,D) CWs of $\mathrm{T}_{1}$ transgenic Brachypodium empty-vector control lines (173 and 175), wild-type
(WT_21-3), and RNAi-RGP1 lines (371, 373, 382, 384, and 393) is presented. Error bars indicate SEM. ${ }^{a, b, c}$ significantly different from EVC_173, EVC_175, and WT_21-3 values, respectively (ANOVA with post hoc Tukey test, alpha $=0.05$. overcoming the limitations in its efficient extraction from plants (CWs).

Opposing but not mutually exclusive views can be taken to improve carbohydrate removal including (1) making the material more "extractable" and (2) increasing the yield of "target" per unit CW. Much work addressing the former has focused on decreasing or altering inhibitors to extractability such as lignin (Vanholme et al., 2012). Alternatively, proposals on increasing cellulose (Delmer and Haigler, 2002) yield have been made. However, approaches focused on cellulose synthase have been hampered due to the complexity of the gene and enzyme regulation (Somerville, 2006; Mutwil et al., 2008; Tan et al., 2015). Recent work suggests that targeted increases in $\beta$-glucans $((1,3 ; 1,4)-\beta$-D-glucans) might prove feasible (Burton et al., 2011). The recent identification and manipulation of regulatory transcription factors has led to ectopic initiation of secondary CW biosynthesis (Wang and Dixon, 2012; Valdivia et al., 2013). However, the targets of these studies were not specific enough to cause beneficial changes in carbohydrate yields without increasing the inhibitory CW aromatics. Recent work in Arabidopsis provides an example of new methods using cell-type specific promoter swapping and engineered feedback loops that can be used to decrease lignin and increase CW carbohydrates
(Yang et al., 2013). The translation of these studies to grasses has not been reported.

In grasses, the CW carbohydrate composition is dominated by Glc, Xyl, and Ara (Pauly and Keegstra, 2008). Given that the CW is a metabolic sink for carbohydrate, we hypothesized that manipulation of the biosynthesis of the nucleotide sugar substrates for CW polysaccharide biosynthesis could lead to beneficial changes in CW composition. Our approach was to systematically target steps in the linear metabolic pathway for conversion of UDP- $\alpha-\mathrm{D}-\mathrm{Glc}$ to UDP- $\beta$-L-Araf in $B$. distachyon through either RNAi-mediated gene suppression or constitutive gene expression of genes encoding enzymes within this pathway. We envisioned several potential outcomes. One example, suppression of the UGD, the first committed step in the pathway, may lead to a metabolic back-up of cytoplasmic UDP-Glc (as seen in Behmüller et al., 2014) that could lead to greater substrate availability for cellulose synthase and/or $\beta$-glucan synthesis and thus potentially stimulate their enzyme activity while relying on endogenous gene expression. In another example, overexpression of a UGD or a UXS could lead to increased xylan production (as seen in alfalfa, Samac et al., 2004). Finally, reductions in the ability to synthesize Ara by suppression of either the UXE or the UDPArap mutase may lead to alterations in arabinoxylan abundance 
and structure thus influencing total FA-mediated crosslinking (Hatfield et al., 1999b; de O Buanafina, 2009) and potentially improving digestibility.

Therefore, we took an approach to generate transgenic $B$. distachyon plants and select them based on two criteria (1) altered CW carbohydrate profiles and (2) near normal overall stature of the plant. From an agronomic perspective, the latter criterion is important to ensure that possible improvements in digestibility are not negated by decreases in yields as observed previously (Reddy et al., 2005; Chen and Dixon, 2007; Shadle et al., 2007). Plants derived from transformation with the RNAiRGP1 (UDP-Arap mutase-1) construct met these criteria and were further characterized.

Analysis of multiple $\mathrm{T}_{1}$ RNAi-RGP1 lines shows that simultaneous suppression of RGP1 and RGP2 in Brachypodium results in decreased CW-bound Ara and hydroxycinnamates. Our data suggests that these CW reductions can result in modest improvements in xylan digestibility but surprisingly, little improvement in cellulose and/or $\beta$-glucan digestibility as indicated by Glc release from the CW (Figures 8B,D). In addition, our results suggest organ-specific responses to the reduction in RGP expression. In leaf blades, though reductions on CW-bound Ara and hydroxycinnamates were comparable to sheath/stem values, the responses of increased lignin in strong expressing RNAi-RGP1 lines (Supplementary Figure S9) as well as the marked reduction of Glc release in all RNAi-RGP1 lines indicate the CW alterations have differing organ-specific affects. The decreased cellulose digestibility may be due to a combination of improved hydrogen bonding of undecorated xylan backbones with cellulose fibrils, organ-specific expression of CW protein(s), and/or increased lignification in response to altered arabinoxylan structure/function. Xylan sans Ara would be linear and suited for strong hydrogen bonding interactions with cellulose and decreased binding accessibility for hydrolytic enzymes. These interactions may be compounded through organ-specific CW protein expression. Additionally, it is unclear how alterations in arabinoxylan structure are sensed and translated into responses of increased lignification. Further experiments are needed to test these hypotheses. These current experiments provide proofin-principle that UDP-Araf biosynthesis could be a target in grasses for designing crops with altered biomass composition without compromising yield. Earlier work by Jung et al. (2011) indicated that reduced ferulates and ferulate mediated crosslinking resulted in increased digestibility of corn silage by dairy cows. Although the available amounts of RNAi-RGP1 material in this study was not sufficient to test digestibility in an animal system, it is most likely that the reduced levels of ferulate crosslinking would result in increased CW digestibility. Microbial ecosystems such as those found in ruminants can do a much better job of breaking down complex CWs compared to individual enzymes. The large array of different microbial species within the rumen can quickly take advantage of niche openings cause by relatively small changes in the CW matrix, e.g., decreased ferulate cross-linking.

Although the RNAi-RGP1 lines did meet the goal of altered $\mathrm{CW}$ composition without major disruption in plant stature, the question remains as to why other constructs did not result in CW compositional changes? Some possibilities for this are presented. (1) The majority of constructs were ineffective in achieving sufficient gene suppression or constitutive expression to influence overall metabolism that manifests as CW composition phenotypes. This could be due to choosing the incorrect gene involved in CW substrate biosynthesis. Alternatively, it is not known how much catalytic flux capacity exists in excess of CW requirements and thus how much downregulation can occur before effects in CW synthesis are observed. Little is known about nucleotide sugar metabolic flux in grasses and how it feeds into the regulation of CW synthesis and other utilizations such as glycoprotein and glycolipid biosynthesis. Analytical platforms have been developed recently to begin addressing the size of plant nucleotide-sugar pools and the flux through them (Alonso et al., 2010; Pabst et al., 2010; Chen et al., 2013a; Behmüller et al., 2014; Ito et al., 2014; Rautengarten et al., 2014). Using new HPLC-MS methods, steady state concentrations of UDP-sugars have been quantified from Arabidopsis T87 cultured cells (Alonso et al., 2010) and leaves (Pabst et al., 2010; Behmüller et al., 2014; Ito et al., 2014), tobacco leaves (Pabst et al., 2010), and rice leaves (Ito et al., 2014). A recent study by Rautengarten et al. (2014) reported on steadystate pools of 13 nucleotide-sugars in nine different Arabidopsis organs and developmental stages. In support of our approach, the work of Behmüller et al. (2014) demonstrated that steady state levels of UDP-sugars downstream of UDP-Glc were reduced in leaves from Arabidopsis ugd2,3 double-mutant plants but the work did not look at whether CW composition phenotypes resulted. Recent metabolic control analysis using Arabidopsis T87 suspension-cultured cells highlighted possible metabolic points where alterations in flux would have pronounced effects on the incorporation of Xyl into a dicot CW (Chen et al., 2013a). It would be of great interest to extend this work to monocots due to their differing CW composition and the number of monocot species used for forage and lignocellulosic biofuel production.

(2) The procedure for Brachypodium transformation involves generation of transgenic embryonic callus followed by plant regeneration. This regeneration process is complicated and presumably involves distinct requirements of the $\mathrm{CW}$ in meeting mechanical and compositional needs to ensure multicellular development progresses appropriately. Given this complexity, manipulation of select metabolic genes to extreme levels (a) could inhibit plant regeneration via CW, glycoprotein, and or glycolipid defects to the point where no plants survived regeneration or (b) mutants with CW phenotypes were culled from our selection process due to not meeting our plant stature requirement. Our results indicate a tolerance in grasses for reduced Ara levels attached to arabinoxylans. UDP-GlcA and UDP-Xyl are inputs for the biosynthesis of pectins and xylans. We speculate that there might be less tolerance for manipulation of UDP-GlcA and UDP-Xyl levels in grasses. Recent work in rice showed decreases in culm CW xylan (decrease of CW Xyl by $14 \%$ ) via a lossof-function glycosyltransferase mutation is achievable resulting in a $29 \%$ increase in total sugar released upon saccharification (Chen et al., 2013b). However, it is unclear whether manipulation of xylan and/or pectins is achievable via substrate biosynthesis 
limitation. Assuming a strong effect on xylan biosynthesis by RNAi-mediated inhibition of UDP-Xyl synthesis, our constitutive promoter RNAi system may not be best suited to adequately test the relationship of UDP-Xyl production to xylan biosynthesis. Having a constitutive inhibition system may pose issues if xylans and/or pectins are critical for early plant development. To circumvent these possible developmental consequences, it would be interesting to explore the use of chemical-inducible systems and/or the use of tissue-/developmental-specific promoters to drive expression of constructs in manipulating nucleotide sugar metabolism in grasses for improved CW composition and digestibility phenotypes. These endeavors are for future work.

Our work has demonstrated that the RGP/UAM gene family can be viable targets for engineering plant CWs with altered CW composition. Using RNAi-mediated gene suppression, Konishi et al. (2011) demonstrated that suppression of OsUAM1 in rice resulted in CW Ara and FA changes. However, the mutant rice plants exhibited dwarfed phenotypes, presumably based on screening for the most severe mutant plants. Their analysis did not include measurement of FA-dimers, important for CW crosslinking, or assessment of CW digestibility. Our work highlights that the selection of mutant plants with normal growth habit is an important and achievable criteria to consider in identifying plant lines with improved biomass characteristics.

\section{Conclusion}

Through the use of RNAi-mediated gene suppression in B. distachyon, we have shown that RNAi-RGP1 plants with near wild-type stature can have significant reductions in RGP1 and $R G P 2$ gene expression, and exhibit reductions in $\mathrm{CW}$-bound

\section{References}

Ahn, J. W., Verma, R., Kim, M., Lee, J. Y., Kim, Y. K., Bang, J. W., et al. (2006). Depletion of UDP-D-apiose/UDP-D-xylose synthases results in rhamnogalacturonan-II deficiency, cell wall thickening, and cell death in higher plants. J. Biol. Chem. 281, 13708-13716. doi: 10.1074/jbc.M5124 03200

Alonso, A. P., Piasecki, R. J., Wang, Y., Laclair, R. W., and Shachar-Hill, Y. (2010). Quantifying the labeling and the levels of plant cell wall precursors using ion chromatography tandem mass spectrometry. Plant Physiol. 153, 915-924. doi: 10.1104/pp.110.155713

Arvidsson, S., Kwasniewski, M., Riano-Pachon, D., and Mueller-Roeber, B. (2008). QuantPrime - a flexible tool for reliable high-throughput primer design for quantitative PCR. BMC Bioinform. 9:465. doi: 10.1186/1471-21059-465

Atmodjo, M. A., Hao, Z., and Mohnen, D. (2013). Evolving views of pectin biosynthesis. Annu. Rev. Plant Biol. 64, 747-779. doi: 10.1146/annurev-arplant042811-105534

Bar-Peled, M., and O’Neill, M. A. (2011). Plant nucleotide sugar formation, interconversion, and salvage by sugar recycling. Annu. Rev. Plant Biol. 62, 127-155. doi: 10.1146/annurev-arplant-042110-103918

Behmüller, R., Forstenlehner, I., Tenhaken, R., and Huber, C. (2014). Quantitative HPLC-MS analysis of nucleotide sugars in plant cells following off-line SPE sample preparation. Anal. Bioanal. Chem. 406, 3229-3237. doi: 10.1007/s00216014-7746-3
Ara and hydroxycinnamate content throughout vegetative aerial plant CWs. The sheath/stem CWs of these plants exhibit up to twofold xylanse digestibility improvements over controls. However, in vitro enzyme-mediated release of Glc from leaf CWs is impeded in $R N A i-R G P 1$ mutants. These data support the efficacy of a selection-scheme where mutant plants of near wild-type stature are screened for CW composition phenotypes. In addition, these data highlight the complexity of grass $\mathrm{CW}$ composition and ways to manipulate that complexity to improve digestibility.

\section{Author Contributions}

All authors of the manuscript meet the essential requirements for publication.

\section{Acknowledgments}

The authors would like to thank Justin Marita and Emily Phillips for their assistance in harvesting plant tissues used for RNA-seq analysis. RNA-seq analysis was partially funded by start up funds from the University of Georgia to RS. The authors would like to thank Nick Santoro and the Great Lakes Bioenergy Research Center, CW Digestibility Platform at Michigan State University for performing the Accelerase 1000 enzyme digestibility analysis on our CW samples.

\section{Supplementary Material}

The Supplementary Material for this article can be found online at: http://journal.frontiersin.org/article/10.3389/fpls.2015.00446

Brkljacic, J., Grotewold, E., Scholl, R., Mockler, T., Garvin, D. F., Vain, P., et al. (2011). Brachypodium as a model for the grasses: today and the future. Plant Physiol. 157, 3-13. doi: 10.1104/pp.111.179531

Burget, E. G., Verma, R., Molhoj, M., and Reiter, W. D. (2003). The biosynthesis of L-arabinose in plants: molecular cloning and characterization of a Golgi-localized UDP-D-xylose 4-epimerase encoded by the MUR4 gene of Arabidopsis. Plant Cell 15, 523-531. doi: 10.1105/tpc.008425

Burton, R. A., Collins, H. M., Kibble, N. A., Smith, J. A., Shirley, N. J., Jobling, S. A., et al. (2011). Over-expression of specific HvCslF cellulose synthase-like genes in transgenic barley increases the levels of cell wall $(1,3 ; 1,4)$-beta-dglucans and alters their fine structure. Plant Biotechnol. J. 9, 117-135. doi: 10.1111/j.1467-7652.2010.00532.x

Carpita, N. C. (1996). Structure and biogenesis of the cell walls of grasses. Annu. Rev. Plant Physiol. Plant Mol. Biol. 47, 445-476. doi: 10.1146/annurev.arplant.47.1.445

Carroll, A., and Somerville, C. (2009). Cellulosic biofuels. Annu. Rev. Plant Biol. 60, 165-182. doi: 10.1146/annurev.arplant.043008.092125

Chen, F., and Dixon, R. A. (2007). Lignin modification improves fermentable sugar yields for biofuel production. Nat. Biotechnol. 25, 759-761. doi: $10.1038 /$ nbt1316

Chen, X., Alonso, A. P., and Shachar-Hill, Y. (2013a). Dynamic metabolic flux analysis of plant cell wall synthesis. Metab. Eng. 18, 78-85. doi: 10.1016/j.ymben.2013.04.006

Chen, X., Vega-Sanchez, M. E., Verhertbruggen, Y., Chiniquy, D., Canlas, P. E., Fagerstrom, A., et al. (2013b). Inactivation of OsIRX10 leads to decreased xylan 
content in rice culm cell walls and improved biomass saccharification. Mol. Plant 6, 570-573. doi: $10.1093 / \mathrm{mp} / \mathrm{sss} 135$

Dai, X., and Zhao, P. X. (2011). psRNATarget: a plant small RNA target analysis server. Nucleic Acids Res. 39, W155-W159. doi: 10.1093/nar/gkr319

de O Buanafina, M. M. (2009). Feruloylation in grasses: current and future perspectives. Mol. Plant 2, 861-872. doi: 10.1093/mp/ssp067

Delgado, I. J., Wang, Z., De Rocher, A., Keegstra, K., and Raikhel, N. V. (1998). Cloning and characterization of AtRGP1. A reversibly autoglycosylated arabidopsis protein implicated in cell wall biosynthesis. Plant Physiol. 116, 1339-1350. doi: 10.1104/pp.116.4.1339

Delmer, D. P., and Haigler, C. H. (2002). The regulation of metabolic flux to cellulose, a major sink for carbon in plants. Metab. Eng. 4, 22-28. doi: 10.1006/mben.2001.0206

Dhugga, K. S., Tiwari, S. C., and Ray, P. M. (1997). A reversibly glycosylated polypeptide (RGP1) possibly involved in plant cell wall synthesis: purification, gene cloning, and trans-Golgi, Äâlocalization. Proc. Natl. Acad. Sci. U.S.A. 94, 7679-7684. doi: 10.1073/pnas.94.14.7679

Doblin, M. S., Johnson, K. L., Humphries, J., Newbigin, E. J., and Bacic, A (2014). Are designer plant cell walls a realistic aspiration or will the plasticity of the plant's metabolism win out? Curr. Opin. Biotech. 26, 108-114. doi: 10.1016/j.copbio.2013.11.012

FAO. (2003). World Agriculture: Towards 2015/2030, An FAO Perspective. London: Earthscan Publications Ltd.

Fukushima, R. S., and Hatfield, R. D. (2001). Extraction and isolation of lignin for utilization as a standard to determine lignin concentration using the acetyl bromide spectrophotometric method. J. Agric. Food Chem. 49, 3133-3139. doi: 10.1021/jf010449r

Girin, T., David, L. C., Chardin, C., Sibout, R., Krapp, A., Ferrario-Mery, S., et al. (2014). Brachypodium: a promising hub between model species and cereals. J. Exp. Bot. 65, 5683-5696. doi: 10.1093/jxb/eru376

Grabber, J. H. (2005). How do lignin composition, structure, and cross-linking affect degradability? A review of cell wall model studies. Crop Sci. 45, 820-831. doi: 10.2135/cropsci2004.0191

Grabber, J. H., Hatfield, R. D., and Ralph, J. (1998a). Diferulate cross-links impede the enzymatic degradation of non-lignified maize walls. J. Sci. Food Agric. 77, 193-200. doi: 10.1002/(SICI)1097-0010(199806)77:2<193::AIDJSFA25>3.0.CO;2-A

Grabber, J. H., Ralph, J., and Hatfield, R. D. (1998b). Ferulate cross-links limit the enzymatic degradation of synthetically lignified primary walls of maize. J. Agric. Food Chem. 46, 2609-2614. doi: 10.1021/jf9800099

Grabber, J. H., Hatfield, R. D., Ralph, J., Zon, J., and Amrhein, N. (1995). Ferulate cross-linking in cell-walls isolated from maize cell-suspensions. Phytochemistry 40, 1077-1082. doi: 10.1016/0031-9422(95)00413-2

Guerche, P., Bellini, C., Le Moullec, J. M., and Caboche, M. (1987). Use of a transient expression assay for the optimization of direct gene transfer into tobacco mesophyll protoplasts by electroporation. Biochimie 69, 621-628. doi: 10.1016/0300-9084(87)90181-7

Hack, H., Bleiholder, H., Buhr, I., Meier, U., Schnock-Fricke, E., Weber, E., et al. (1992). Einheitliche codienrung der phanologischen entwicklungsstadien mono-und dikotyler pflanzen-erweiterte BBCH-skala, Allgemein. Nachri. Dtsch. Pflanzenschutzd. 44, 265-270.

Hajdukiewicz, P., Svab, Z., and Maliga, P. (1994). The small, versatile pPZP family of Agrobacterium binary vectors for plant transformation. Plant Mol. Biol. 25, 989-994. doi: 10.1007/BF00014672

Harper, A. D., and Bar-Peled, M. (2002). Biosynthesis of UDP-xylose. Cloning and characterization of a novel Arabidopsis gene family, UXS, encoding soluble and putative membrane-bound UDP-glucuronic acid decarboxylase isoforms. Plant Physiol. 130, 2188-2198. doi: 10.1104/pp.009654

Hatfield, R. D., Grabber, J., Ralph, J., and Brei, K. (1999a). Using the acetyl bromide assay to determine lignin concentrations in herbaceous plants: some cautionary notes. J. Agric. Food Chem. 47, 628-632. doi: 10.1021/jf9808776

Hatfield, R. D., Helm, R. F., and Ralph, J. (1991). Synthesis of methyl 5-O-transferuloyl-alpha-L-arabinofuranoside and its use as a substrate to assess feruloyl esterase activity. Anal. Biochem. 194, 25-33. doi: 10.1016/0003-2697(91) 90146-K

Hatfield, R. D., and Marita, J. M. (2010). Enzymatic processes involved in the incorporation of hydroxycinnamates into grass cell walls. Phytochem. Rev. 9, 35-45. doi: 10.1007/s11101-010-9165-1
Hatfield, R. D., Ralph, J., and Grabber, J. H. (1999b). Cell wall cross-linking by ferulates and diferulates in grasses. J. Sci. Food Agric. 79, 403-407. doi: 10.1002/(SICI)1097-0010(19990301)79:3<403::AID-JSFA263>3.0.CO;2-0

Hatfield, R. D., Ralph, J., and Grabber, J. H. (1999c). Cell wall structural foundations: molecular basis for improving forage digestibilities. Crop Sci. 39, 27-37. doi: 10.2135/cropsci1999.0011183X0039000 $10005 \mathrm{x}$

Hatfield, R. D., Marita, J. M., Frost, K., Grabber, J., Ralph, J., Lu, F., et al. (2009). Grass lignin acylation: p-coumaroyl transferase activity and cell wall characteristics of C3 and C4 grasses. Planta 229, 1253-1267. doi: $10.1007 / \mathrm{s} 00425-009-0900-\mathrm{z}$

Hong, S. Y., Park, J. H., Cho, S. H., Yang, M. S., and Park, C. M. (2011). Phenological growth stages of Brachypodium distachyon: codification and description. Weed Res. 51, 612-620. doi: 10.1111/j.1365-3180.2011.00877.x

Hong, S.-Y., Seo, P., Yang, M.-S., Xiang, F., and Park, C.-M. (2008). Exploring valid reference genes for gene expression studies in Brachypodium distachyon by real-time PCR. BMC Plant Biol. 8:112. doi: 10.1186/1471-22298-112

International Brachypodium Initiative. (2010). Genome sequencing and analysis of the model grass Brachypodium distachyon. Nature 463, 763-768. doi: 10.1038 /nature08747

Ito, J., Herter, T., Baidoo, E. E., Lao, J., Vega-Sanchez, M. E., Michelle SmithMoritz, A., et al. (2014). Analysis of plant nucleotide sugars by hydrophilic interaction liquid chromatography and tandem mass spectrometry. Anal. Biochem. 448, 14-22. doi: 10.1016/j.ab.2013.11.026

Jung, H. G., Mertens, D. R., and Phillips, R. L. (2011). Effect of reduced ferulate-mediated lignin/arabinoxylan cross-linking in corn silage on feed intake, digestibility, and milk production. J. Dairy Sci. 94, 5124-5137. doi: 10.3168/jds.2011-4495

Jung, H. J., Samac, D. A., and Sarath, G. (2012). Modifying crops to increase cell wall digestibility. Plant Sci. 185-186, 65-77. doi: 10.1016/j.plantsci.2011. 10.014

Kalluri, U. C., Yin, H., Yang, X., and Davison, B. H. (2014). Systems and synthetic biology approaches to alter plant cell walls and reduce biomass recalcitrance. Plant Biotechnol. J. 12, 1207-1216. doi: 10.1111/pbi.12283

Kang, B. H., Busse, J. S., Dickey, C., Rancour, D. M., and Bednarek, S. Y. (2001). The arabidopsis cell plate-associated dynamin-like protein, ADL1Ap, is required for multiple stages of plant growth and development. Plant Physiol. 126, 47-68. doi: 10.1104/pp.126.1.47

Karkonen, A., Murigneux, A., Martinant, J. P., Pepey, E., Tatout, C., Dudley, B. J., et al. (2005). UDP-glucose dehydrogenases of maize: a role in cell wall pentose biosynthesis. Biochem. J. 391, 409-415. doi: 10.1042/bj200 50800

Kim, D., Pertea, G., Trapnell, C., Pimentel, H., Kelley, R., and Salzberg, S. L. (2013). TopHat2: accurate alignment of transcriptomes in the presence of insertions, deletions and gene fusions. Genome Biol. 14, R36. doi: 10.1186/gb-201314-4-r36

Kim, H., and Ralph, J. (2010). Solution-state 2D NMR of ball-milled plant cell wall gels in DMSO-d(6)/pyridine-d(5). Org. Biomol. Chem. 8, 576-591. doi: $10.1039 / \mathrm{b} 916070 \mathrm{a}$

Klinghammer, M., and Tenhaken, R. (2007). Genome-wide analysis of the UDP-glucose dehydrogenase gene family in Arabidopsis, a key enzyme for matrix polysaccharides in cell walls. J. Exp. Bot. 58, 3609-3621. doi: 10.1093/jxb/erm209

Konishi, T., Aohara, T., Igasaki, T., Hayashi, N., Miyazaki, Y., Takahashi, A., et al. (2011). Down-regulation of UDP-arabinopyranose mutase reduces the proportion of arabinofuranose present in rice cell walls. Phytochemistry 72, 1962-1968. doi: 10.1016/j.phytochem.2011.07.012

Konishi, T., Takeda, T., Miyazaki, Y., Ohnishi-Kameyama, M., and Hayashi, T. (2007). A plant mutase that interconverts UDP-arabinofuranose and UDP-arabinopyranose. Glycobiology 17, 345-354. doi: 10.1093/glycob/ cwl081

Kotake, T., Takata, R., Verma, R., Takaba, M., Yamaguchi, D., Orita, T., et al. (2009). Bifunctional cytosolic UDP-glucose 4-epimerases catalyse the interconversion between UDP-D-xylose and UDP-L-arabinose in plants. Biochem. J. 424, 169177. doi: 10.1042/BJ20091025

Langmead, B., and Salzberg, S. L. (2012). Fast gapped-read alignment with Bowtie 2. Nat. Methods 9, 357-359. doi: 10.1038/nmeth.1923 
Lazo, G. R., Stein, P. A., and Ludwig, R. A. (1991). A DNA transformationcompetent Arabidopsis genomic library in Agrobacterium. Biotechnology (N. Y.) 9, 963-967. doi: 10.1038/nbt1091-963

Madden, T. L. (2013). “The BLAST sequence analysis tool”, in The NCBI Handbook, 2nd Edn, eds J. McEntyre and J. Ostell (Bethesda, MD: National Center for Biotechnology information).

Marita, J. M., Hatfield, R. D., Rancour, D. M., and Frost, K. E. (2014). Identification and suppression of the p-coumaroyl CoA:hydroxycinnamyl alcohol transferase in Zea mays L. Plant J. 78, 850-864. doi: 10.1111/tpj.12510

Marita, J. M., Vermerris, W., Ralph, J., and Hatfield, R. D. (2003). Variations in the cell wall composition of maize brown midrib mutants. J. Agric. Food Chem. 51, 1313-1321. doi: 10.1021/jf0260592

Masuko, T., Minami, A., Iwasaki, N., Majima, T., Nishimura, S.-I., and Lee, Y. C. (2005). Carbohydrate analysis by a phenol-sulfuric acid method in microplate format. Anal. Biochem. 339, 69-72. doi: 10.1016/j.ab.2004. 12.001

McCann, M. C., and Carpita, N. C. (2008). Designing the deconstruction of plant cell walls. Curr. Opin. Plant Biol. 11, 314-320. doi: 10.1016/j.pbi.2008.04.001

Miki, D., Itoh, R., and Shimamoto, K. (2005). RNA silencing of single and multiple members in a gene family of rice. Plant Physiol. 138, 1903-1913. doi: 10.1104/pp.105.063933

Miki, D., and Shimamoto, K. (2004). Simple RNAi vectors for stable and transient suppression of gene function in rice. Plant Cell Physiol. 45, 490-495. doi: $10.1093 / \mathrm{pcp} / \mathrm{pch} 048$

Mølhøj, M., Verma, R., and Reiter, W.-D. (2003). The biosynthesis of the branchedchain sugar D-apiose in plants: functional cloning and characterization of a UDP-D-apiose UDP-D-xylose synthase from Arabidopsis. Plant J. 35, 693-703. doi: 10.1046/j.1365-313X.2003.01841.x

Mur, L. A. J., Allainguillaume, J., Catalan, P., Hasterok, R., Jenkins, G., Lesniewska, K., et al. (2011). Exploiting the brachypodium tool box in cereal and grass research. New Phytol. 191, 334-347. doi: 10.1111/j.14698137.2011.03748.x

Mutwil, M., Debolt, S., and Persson, S. (2008). Cellulose synthesis: a complex complex. Curr. Opin. Plant Biol. 11, 252-257. doi: 10.1016/j.pbi.2008.03.007

Ogawa, Y., Dansako, T., Yano, K., Sakurai, N., Suzuki, H., Aoki, K., et al. (2008). Efficient and high-throughput vector construction and Agrobacteriummediated transformation of Arabidopsis thaliana suspension-cultured cells for functional genomics. Plant Cell Physiol. 49, 242-250. doi: 10.1093/pcp/ pcm 181

Pabst, M., Grass, J., Fischl, R., Leãåonard, R., Jin, C., Hinterkoãàrner, G., et al. (2010). Nucleotide and nucleotide sugar analysis by liquid chromatography-electrospray ionization-mass spectrometry on surfaceconditioned porous graphitic carbon. Anal. Chem. 82, 9782-9788. doi: 10.1021/ ac101975k

Pattathil, S., Harper, A. D., and Bar-Peled, M. (2005). Biosynthesis of UDPxylose: characterization of membrane-bound AtUxs2. Planta 221, 538-548. doi: 10.1007/s00425-004-1471-7

Pauly, M., and Keegstra, K. (2008). Cell-wall carbohydrates and their modification as a resource for biofuels. Plant J. 54, 559-568. doi: 10.1111/j.1365313X.2008.03463.x

Pauly, M., and Keegstra, K. (2010). Plant cell wall polymers as precursors for biofuels. Curr. Opin. Plant Biol. 13, 305-312. doi: 10.1016/j.pbi.2009.12.009

Petrik, D. L., Karlen, S. D., Cass, C. L., Padmakshan, D., Lu, F., Liu, S., et al. (2014). p-Coumaroyl-CoA:monolignol transferase (PMT) acts specifically in the lignin biosynthetic pathway in Brachypodium distachyon. Plant J. 77, 713-726. doi: 10.1111/tpj.12420

Philippe, V. (2011). Brachypodium as a model system for grass research. J. Cereal Sci. 54, 1-7. doi: 10.1016/j.jcs.2011.04.002

Ralph, J., Bunzel, M., Marita, J. M., Hatfield, R. D., Lu, F., Kim, H., et al. (2004). Peroxidase-dependent cross-linking reactions of p-hydroxycinnamates in plant cell walls. Phytochem. Rev. 3, 79-96. doi: 10.1023/B:PHYT.0000047811. 13837.fb

Ramakers, C., Ruijter, J. M., Deprez, R. H. L., and Moorman, A. F. M. (2003). Assumption-free analysis of quantitative real-time polymerase chain reaction (PCR) data. Neurosci. Lett. 339, 62-66. doi: 10.1016/s0304-3940(02)01423-4

Rancour, D. M., Marita, J. M., and Hatfield, R. D. (2012). Cell wall composition throughout development for the model grass Brachypodium distachyon. Front. Plant Sci. 3:266. doi: 10.3389/fpls.2012.00266
Rautengarten, C., Ebert, B., Herter, T., Petzold, C. J., Ishii, T., Mukhopadhyay, A., et al. (2011). The interconversion of UDP-Arabinopyranose and UDPArabinofuranose is indispensable for plant development in Arabidopsis. Plant Cell 23, 1373-1390. doi: 10.1105/tpc.111.083931

Rautengarten, C., Ebert, B., Moreno, I., Temple, H., Herter, T., Link, B., et al. (2014). The golgi localized bifunctional UDP-rhamnose/UDP-galactose transporter family of Arabidopsis. Proc. Natl. Acad. Sci. U.S.A. 111, 1156311568. doi: 10.1073/pnas.1406073111

Reboul, R., Geserick, C., Pabst, M., Frey, B., Wittmann, D., Lütz-Meindl, U., et al. (2011). Down-regulation of UDP-glucuronic acid biosynthesis leads to swollen plant cell walls and severe developmental defects associated with changes in pectic polysaccharides. J. Biol. Chem. 286, 39982-39992. doi: 10.1074/jbc.M111.255695

Reddy, M. S., Chen, F., Shadle, G., Jackson, L., Aljoe, H., and Dixon, R. A. (2005). Targeted down-regulation of cytochrome P450 enzymes for forage quality improvement in alfalfa (Medicago sativa L.). Proc. Natl. Acad. Sci. U.S.A. 102, 16573-16578. doi: 10.1073/pnas.0505749102

Reiter, W. D. (2008). Biochemical genetics of nucleotide sugar interconversion reactions. Curr. Opin. Plant Biol. 11, 236-243. doi: 10.1016/j.pbi.2008. 03.009

Samac, D., Litterer, L., Temple, G., Jung, H.-J., and Somers, D. (2004). Expression of UDP-glucose dehydrogenase reduces cell-wall polysaccharide concentration and increases xylose content in alfalfa stems. Appl. Biochem. Biotechnol. 116, 1167-1182. doi: 10.1385/ABAB:116:1-3:1167

Santoro, N., Cantu, S., Tornqvist, C.-E., Falbel, T., Bolivar, J., Patterson, S., et al. (2010). A high-throughput platform for screening milligram quantities of plant biomass for lignocellulose digestibility. Bioenergy Res. 3, 93-102. doi: 10.1007/s12155-009-9074-6

Scheller, H. V., and Ulvskov, P. (2010). Hemicelluloses. Annu. Rev. Plant Biol. 61, 263-289. doi: 10.1146/annurev-arplant-042809-112315

Shadle, G., Chen, F., Srinivasa Reddy, M. S., Jackson, L., Nakashima, J., and Dixon, R. A. (2007). Down-regulation of hydroxycinnamoyl CoA: shikimate hydroxycinnamoyl transferase in transgenic alfalfa affects lignification, development and forage quality. Phytochemistry 68, 1521-1529. doi: 10.1016/j.phytochem.2007.03.022

Somerville, C. (2006). Cellulose synthesis in higher plants. Annu. Rev. Cell Dev. Biol. 22, 53-78. doi: 10.1146/annurev.cellbio.22.022206.160206

Sullivan, M. (2009). A novel red clover hydroxycinnamoyl transferase has enzymatic activities consistent with a role in phaselic acid biosynthesis. Plant Physiol. 150, 1866-1879. doi: 10.1104/pp.109.136689

Suzuki, K., Suzuki, Y., and Kitamura, S. (2003). Cloning and expression of a UDPglucuronic acid decarboxylase gene in rice. J. Exp. Bot. 54, 1997-1999. doi: $10.1093 /$ jxb/erg203

Suzuki, K., Watanabe, K., Masumura, T., and Kitamura, S. (2004). Characterization of soluble and putative membrane-bound UDP-glucuronic acid decarboxylase (OsUXS) isoforms in rice. Arch. Biochem. Biophys. 431, 169-177. doi: 10.1016/j.abb.2004.08.029

Tan, H. T., Shirley, N. J., Singh, R. R., Henderson, M., Dhugga, K. S., Mayo, G. M., et al. (2015). Powerful regulatory systems and post-transcriptional gene silencing resist increases in cellulose content in cell walls of barley. BMC Plant Biol. 15:62. doi: 10.1186/s12870-015-0448-y

Tenhaken, R., and Thulke, O. (1996). Cloning of an enzyme that synthesizes a key nucleotide-sugar precursor of hemicellulose biosynthesis from soybean:UDP-Glucose dehydrogenase. Plant Physiol. 112, 1127-1134. doi: 10.1104/pp.112.3.1127

Torbert, K. A., Rines, H. W., and Somers, D. A. (1995). Use of paromomycin as a selective agent for oat transformation. Plant Cell Rep. 14, 635-640. doi: 10.1007/BF00232728

Trapnell, C., Hendrickson, D. G., Sauvageau, M., Goff, L., Rinn, J. L., and Pachter, L. (2013). Differential analysis of gene regulation at transcript resolution with RNA-seq. Nat. Biotechnol. 31, 46-53. doi: 10.1038/nbt.2450

Valdivia, E. R., Herrera, M. T., Gianzo, C., Fidalgo, J., Revilla, G., Zarra, I., et al. (2013). Regulation of secondary wall synthesis and cell death by NAC transcription factors in the monocot Brachypodium distachyon. J. Exp. Bot. 64, 1333-1343. doi: 10.1093/jxb/ers394

Vanholme, R., Morreel, K., Darrah, C., Oyarce, P., Grabber, J. H., Ralph, J., et al. (2012). Metabolic engineering of novel lignin in biomass crops. New Phytol. 196, 978-1000. doi: 10.1111/j.1469-8137.2012.04337.x 
Vogel, J., and Hill, T. (2008). High-efficiency Agrobacterium-mediated transformation of Brachypodium distachyon inbred line Bd21-3. Plant Cell Rep. 27, 471-478. doi: 10.1007/s00299-007-0472-y

Wang, H. Z., and Dixon, R. A. (2012). On-off switches for secondary cell wall biosynthesis. Mol. Plant 5, 297-303. doi: 10.1093/mp/ssr098

Watson, J. M., Fusaro, A. F., Wang, M., and Waterhouse, P. M. (2005). RNA silencing platforms in plants. FEBS Lett. 579, 5982-5987. doi: 10.1016/j.febslet.2005.08.014

Wesley, S. V., Helliwell, C. A., Smith, N. A., Wang, M. B., Rouse, D. T., Liu, Q., et al. (2001). Construct design for efficient, effective and high-throughput gene silencing in plants. Plant J. 27, 581-590. doi: 10.1046/j.1365-313X.2001. 01105.x

Yang, F., Mitra, P., Zhang, L., Prak, L., Verhertbruggen, Y., Kim, J. S., et al. (2013). Engineering secondary cell wall deposition in plants. Plant Biotechnol. J. 11, 325-335. doi: 10.1111/pbi.12016

Ye, J., Coulouris, G., Zaretskaya, I., Cutcutache, I., Rozen, S., and Madden, T. L. (2012). Primer-BLAST: a tool to design target-specific primers for polymerase chain reaction. BMC Bioinform. 13:134. doi: 10.1186/1471-210513-134

Yin, Y., Huang, J., Gu, X., Bar-Peled, M., and Xu, Y. (2011). Evolution of plant nucleotide-sugar interconversion enzymes. PLOS ONE 6:e27995. doi: 10.1371/journal.pone.0027995

Conflict of Interest Statement: The authors declare that the research was conducted in the absence of any commercial or financial relationships that could be construed as a potential conflict of interest.

Copyright (c) 2015 Rancour, Hatfield, Marita, Rohr and Schmitz. This is an openaccess article distributed under the terms of the Creative Commons Attribution License (CC BY). The use, distribution or reproduction in other forums is permitted, provided the original author(s) or licensor are credited and that the original publication in this journal is cited, in accordance with accepted academic practice. No use, distribution or reproduction is permitted which does not comply with these terms. 